\title{
Emerging anti-inflammatory strategies for COPD
}

\author{
Mario Cazzola*,\#, Clive P. Pageø, Luigino Calzetta* and M. Gabriella Matera ${ }^{+}$
}

\begin{abstract}
The hallmark of chronic obstructive pulmonary disease (COPD) is an enhanced or abnormal inflammatory immune response of the lungs to inhaled particles and gases, usually from cigarette smoke, characterised by increased numbers of neutrophils, activated macrophages and activated T-lymphocytes (Tc1 and Th1 cells). Therefore, suppression of the inflammatory response is a logical approach to the treatment of COPD. Despite the inflammatory nature of COPD, currently available anti-inflammatory therapies provide little or no benefit in COPD patients and may have detrimental effects. For this reason, there is an urgent need to discover effective and safe anti-inflammatory treatments that might prevent the relentless progression of the disease. In recent years, attention has largely been focused on inhibition of recruitment and activation of inflammatory cells, and on antagonism of their products. In this review, we put together a summary of the state-of-the-art development of clearly and/or potentially useful antiinflammatory strategies in COPD.
\end{abstract}

KEYWORDS: Chronic obstructive pulmonary disease, targeted therapy, therapeutic interventions, treatment of chronic obstructive pulmonary disease

everal mechanistic concepts have been implicated in the pathogenesis of chronic obstructive pulmonary disease (COPD) [1]. The hallmark of COPD is an enhanced or abnormal inflammatory immune response of the lungs to inhaled particles and gases, usually from cigarette smoke, characterised by increased numbers of neutrophils, activated macrophages and activated T-lymphocytes (Tc1 and Th1 cells). Therefore, suppression of the inflammatory response is a logical approach to the treatment of COPD that might improve symptoms such as cough and mucus secretion, improve health status and reduce exacerbations. In the long-term, such treatments should reduce disease progression. However, hitherto, there is still no effective anti-inflammatory treatment also because inflammation in patients with COPD is at least partly glucocorticoid-resistant, likely because cigarette smoking and oxidative stress impair histone deacetylase 2 (HDAC2) function [2]. In any case, only a limited number of drugs have been shown to influence the numbers of the important inflammatory cells, macrophages, neutrophils and T-lymphocytes, in the lungs of patients with COPD.

It is clear that there is a huge unmet medical need with regard to effective anti-inflammatory agents to treat COPD patients. For this reason, attention has largely been focused on inhibition of recruitment and activation of these cells, and on antagonism of their products, although it is not uncommon for many classes of drugs to carry out these two actions simultaneously. In addition, there are drugs that may have indirect anti-inflammatory action.

\section{DRUGS THAT DIRECTLY INFLUENCE THE CELLULAR COMPONENTS OF INFLAMMATION}

At present, some new drugs directly inhibit the cellular components of inflammation, although there are concerns about their use because an impaired neutrophilic response can increase the susceptibility to infection in patients with COPD, who are often already at risk [3]. The therapies explored include phosphodiesterase 4 (PDE4) inhibitors, adenosine $\mathrm{A}_{2 \mathrm{a}}$-receptor agonists and drugs that interfere with adhesion molecules (table 1 ).

\section{PDE4 inhibitors}

The PDE4 isoenzyme is a major therapeutic target because it is the predominant isoenzyme in the majority of inflammatory cells implicated in the pathogenesis of COPD. Its inhibition in inflammatory cells influences several specific responses, such as the production and/or release of

\section{AFFILIATIONS}

*Dept of System Medicine, Unit of Respiratory Clinical Pharmacology, University of Rome "Tor Vergata",

\#Dept of Pulmonary Rehabilitation, San Raffaele Pisana Hospital, IRCCS, Rome,

${ }^{+}$Dept of Experimental Medicine, Unit of Pharmacology, Second University of Naples, Naples, Italy.

- Sackler Institute of Pulmonary

Pharmacology, Institute of

Pharmaceutical Science, King's

College London, London, UK.

CORRESPONDENCE

Mario Cazzola

Dept of System Medicine,

University of Rome Tor Vergata

Via Montpellier 1

Rome 00133

Italy

E-mail: mario.cazzola@uniroma2.it

Received:

Dec 062011

Accepted after revision:

March 052012

First published online:

April 102012

European Respiratory Journal

Print ISSN 0903-1936

Online ISSN 1399-3003 
TABLE 1 Drugs that directly influence the cellular components of inflammation

\begin{tabular}{|c|c|c|c|}
\hline PDE4 inhibitors & $\begin{array}{l}\text { Intensely investigated substances } \\
\text { Reduction in airway tissue inflammatory } \\
\text { cells characteristic of COPD } \\
\text { Fewer exacerbations } \\
\text { Stabilisation of FEV1 over time }\end{array}$ & $\begin{array}{l}\text { Contradictory results with different } \\
\text { compounds } \\
\text { Gastrointestinal side-effects } \\
\text { Some anti-inflammatory effects reported in vitro } \\
\text { might not be expressed at plasma levels } \\
\text { that are attained in humans } \\
\text { Delayed apoptosis of neutrophils }\end{array}$ & $\begin{array}{l}\text { Oral PDE4 inhibitors } \\
\text { Roflumilast } \\
\text { ELB353 } \\
\text { Revamilast } \\
\text { MEM1414 } \\
\text { Oglemilast } \\
\text { OX914 } \\
\text { BLX-028914 } \\
\text { ASP3258 } \\
\text { TAS-203 } \\
\text { Zl-n-91 } \\
\text { NIS-62949 } \\
\text { NCS 613 } \\
\text { Tetomilast } \\
\text { Inhaled PDE4 inhibitors } \\
\text { GSK256066 } \\
\text { SCH900182 } \\
\text { Compound } 1 \\
\text { Tofimilast } \\
\text { AWD12-281 } \\
\text { UK500001 } \\
\text { PDE3/4 inhibitors } \\
\text { RPL554 } \\
\text { PDE4/7 inhibitors } \\
\text { TPI 1100 }\end{array}$ \\
\hline $\begin{array}{l}\text { Adenosine } \\
\text { A2a-receptor } \\
\text { agonists }\end{array}$ & $\begin{array}{l}\text { Activation of adenosine } \mathrm{A}_{2 \mathrm{a}} \text {-receptors } \\
\text { mediates marked anti-inflammatory } \\
\text { activity, both in vitro and in vivo }\end{array}$ & Cardiovascular side-effects & $\begin{array}{l}\text { CGS21680 } \\
\text { ATL146e } \\
\text { UK371,104 } \\
\text { GW328267X } \\
\text { Regadenoson } \\
\text { 2-(cyclohexylethylthio)-AMP }\end{array}$ \\
\hline
\end{tabular}

PDE4: phosphodiesterase 4; COPD: chronic obstructive pulmonary disease; FEV1: forced expiratory volume in $1 \mathrm{~s}$; mAb: monoclonal antibodies.

proinflammatory mediators, including cytokines and active oxygen species [4], with well-documented effects in animal models of COPD [5]. PDE4 is also present in airway smooth muscle, but to date selective PDE4 inhibitors have not shown acute bronchodilator activity in humans [6, 7].

Most of the (long-term) studies in COPD so far have been performed with the second generation of oral PDE4-inhibitors, cilomilast and roflumilast [8]. The development of cilomilast was terminated because large multicentre phase III trials failed to meet their pre-defined efficacy end-points and were frequently associated with gastrointestinal side-effects. On the contrary, roflumilast has been registered in several European countries and approved in the USA.

Several 6- to 12-month randomised clinical trials (RCTs) have shown that roflumilast offered sustained clinical efficacy, mainly in terms of decreases in exacerbations, in a subset of COPD patients whose characteristics included chronic bronchitis with/without concurrent inhaled glucocorticoid [9]. Importantly, it decreased the rate of COPD exacerbations and improved lung function (pre- and post-bronchodilator forced expiratory volume in $1 \mathrm{~s}(\mathrm{FEV} 1)$ ) despite concomitant treatment with long-acting $\beta_{2}$-agonists [10]. A pooled data analysis 
showed that side-effects associated with roflumilast (nausea, headache, diarrhoea and weight loss) were usually not severe and self-limiting, although resulted in an increased patient withdrawal across the studies [8].

Several other oral PDE4 inhibitors are still under development (table 1), although to date, the therapeutic usefulness of oral PDE4 inhibitors is limited by their side-effects, particularly vomiting and nausea (table 1) [6,8].

It has been suggested that these side-effects are due to inhibition of a particular subtype of PDE4, the PDE4D [11], whereas PDE4B is more important than PDE4D in inflammatory cells [12]. Theoretically, PDE4B-selective inhibitors might have a greater therapeutic ratio [8]. However, this viewpoint in not universally shared and the recent discovery of selective brainpenetrant PDE4 inhibitors that are devoid of emesis [13] adds further weight against avoiding the targeting of PDE4D, particularly as this enzyme subtype is expressed in cells of interest to COPD [8].

Alternatively, PDE4 inhibitors with low oral bioavailability could be administered by inhalation to maximise their efficacy in the treatment of inflammatory disease while minimising their side-effects. Several inhaled PDE4 inhibitors, for instance GSK256066, are under development, but failures in clinical trials have been reported for three other inhaled PDE4 inhibitors, tofimilast [14], AWD12-281 [15] and UK500001 [16].

Another approach is the development of mixed PDE3/4 inhibitors with the goal of having bronchodilator and anti-inflammatory activities in a single molecule (fig. 1). The development of mixed PDE3/4 inhibitors with long duration of action coupled with anti-inflammatory activity could be of greater utility in COPD because the combination of both bronchodilator (PDE3-mediated) and anti-inflammatory activity (PDE3- and PDE4-mediated) could

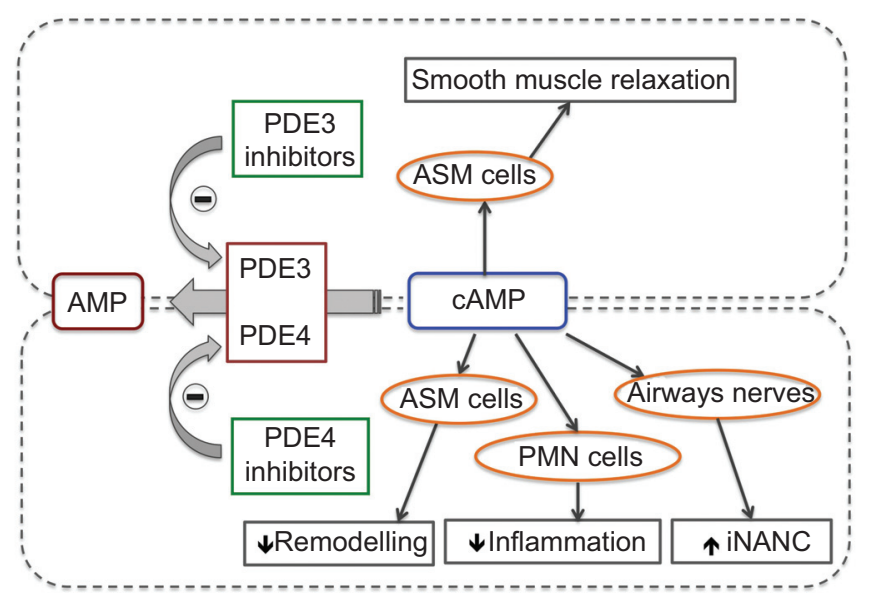

FIGURE 1. Combined inhibition of phosphodiesterase (PDE)3 and PDE4 inhibitors has additive and synergistic anti-inflammatory and bronchodilatory effects versus inhibition of either PDE3 or PDE4 alone. The mechanism(s) underlying the apparent synergistic effects of dual PDE3/4 inhibition are unclear. It has, however, been suggested that PDE3 (which is predominantly localised to the particulate cellular fraction) and PDE4 (which is predominantly cytosolic) can regulate different pools of CAMP. ASM: airway smooth muscle; PMN: polymorphonuclear neutrophil; iNANC: inhibitory non-adrenergic and non-cholinergic. result in an enhanced overall efficacy profile compared to selective PDE4 inhibitors. RPL 554 is the most advanced mixed PDE3/4 inhibitor under development [17].

In addition, mixed PDE4/7 inhibitors are under development. The combination of PDE7 inhibition with PDE4 inhibition could, in theory, be synergistic in reducing inflammatory cell activation and chemokine and cytokine release in the lungs [8]. TPI 1100 is comprised of two antisense oligonucleotides targeting the mRNA for the PDE4B/4D and PDE 7A isoforms [18]. It is very effective in reducing neutrophil influx and key cytokines in an established smoking mouse model of COPD [18].

\section{Adenosine $A_{2 a}$-receptor agonists}

There is evidence suggesting the involvement of adenosine receptors in the process of inflammation. To date, four subtypes $\left(\mathrm{A}_{1}, \mathrm{~A}_{2 \mathrm{a}}, \mathrm{A}_{2 \mathrm{~b}}\right.$ and $\left.\mathrm{A}_{3}\right)$ of adenosine receptors have been cloned. The anti-inflammatory effects of adenosine are generally attributed to occupancy of cyclic adenosine monophosphate (cAMP)-elevating $\mathrm{G}_{\mathrm{s}}$-protein-coupled $\mathrm{A}_{2 \mathrm{a}}$-receptors [19]. A key molecular mechanism is the suppression of the nuclear factor (NF)- $\mathrm{\kappa B}$ pathway activated by cytokines such as tumour necrosis factor (TNF)- $\alpha$ and interleukin (IL)-1 $\beta$. The stimulation of $\mathrm{A}_{2 \mathrm{a}}$-receptors limits macrophage proinflammatory cytokine production, reduces adhesion molecule expression on endothelial cells, and suppresses the generation of superoxide anion and leukotriene synthesis by neutrophils [20-22].

Several adenosine $\mathrm{A}_{2 \mathrm{a}}$-receptor agonists have been reported to be effective in models of COPD (table 1), but potential problems may result from cardiovascular side-effects, mainly hypotension and reflex tachycardia [20, 22]. Regadenoson (CVT-3146), a selective adenosine $\mathrm{A}_{2 \mathrm{a}}$-receptor agonist, was safe in compromised outpatients with clinically stable moderate to severe COPD, but unable to modify multiple lung function parameters, including repeated FEV1 and forced vital capacity (FVC) when compared to placebo [23]. Nevertheless, UK432,097, which is beneficial in the lungs of anaesthetised guinea pig without any obvious cardiovascular side-effects, and likely GW328267X, which is a highly potent $\mathrm{A}_{2 \mathrm{~A}}$-receptor agonist, are currently in phase II trials for COPD. Reports on the effect of these compounds in COPD are awaited with interest.

Recently, it has been proposed to develop $\mathrm{A}_{2 \mathrm{a}}$-receptor agonists as prodrugs by synthesising inactive, phosphorylated forms of $\mathrm{A}_{2 \mathrm{a}}$-receptor agonists $[24,25]$. This approach may help to achieve desired anti-inflammatory actions and decrease unwanted side-effects, such as hypotension.

\section{Drugs that interfere with adhesion molecules}

Inflammatory processes in COPD are characterised by a continuous migration of inflammatory cells, mainly neutrophils, from the vascular compartment to the lung, which is partly regulated by selectins [26]. Selectins mediate transient adhesive interactions pertinent to inflammation through the recognition of the carbohydrate epitope, sialyl Lewis ${ }^{x}\left(\operatorname{sLe}^{x}\right)$, expressed on structurally diverse protein-lipid ligands on circulating leukocytes. The rapid turnover of selectin-ligand bonds, due to their fast on- and off-rates along with their remarkably high tensile strengths, enables them to mediate cell tethering and rolling in shear flow [27]. Three selectins have been identified: L-, P- and E-selectin. 
It has been postulated that targeting these molecules might reduce the inflammation in COPD [28]. Definitely the most common approach in inhibiting selectin function is by direct inhibition of one or more of the selectins. Carbohydrates, recombinant soluble ligands, antibodies and small-molecule inhibitors have all entered clinical development as potential therapeutic agents targeting selectins (table 1 ).

Bimosiamose (TBC1269, 1) is a synthetic pan-selectin antagonist that targets E-, P-, and L-selectin. In vitro, bimosiamose blocks adhesion of neutrophils, eosinophils and lymphocytes under static and dynamic flow conditions [29]. In vivo, it showed antiinflammatory efficacy in various animal models, including models of lung inflammation [30]. In a pilot trial, inhaled bimosiamose was safe and well tolerated in patients with stable mild to moderate COPD and showed encouraging anti-inflammatory effects on sputum parameters, reducing IL-8 level and lymphocytes [31]. Another more recent trial documented that inhalation of bimosiamose for 28 days on top of standard bronchodilators was safe and well tolerated in 77 patients with moderate to severe COPD (Global Initiative for Chronic Obstructive Lung Disease stage II-III) [32]. It led to a broad and significant attenuation of airway inflammation and trend towards lung function improvements. Obviously, further studies are required to demonstrate a true clinical benefit bimosiamose in patients with COPD.

Heparin is a known inhibitor of selectin-mediated interactions. PGX-100 (2-O, 3-O desulfated heparin) and PGX-200, the inhaled formulation of PGX-100, have been developed to maximise the anti-selectin activity of heparin, while minimising the anti-coagulant effect, but a PGX-100 phase Ilb trial in patients with acute exacerbation of COPD was terminated due to the results from the interim analysis showing evidence of safety without efficacy [33].

EL246, an anti-selectin monoclonal antibody (mAb) that binds to a specific antigenic determinant on both E- and L-selectins and inhibits their cell adhesion function, is under predevelopment for the treatment of acute exacerbations of COPD [33].

\section{INHIBITORS OF INFLAMMATORY MEDIATORS}

Cytokines and chemokines regulate migration and activation of a range of inflammatory cells in COPD and there is now an intensive search for compounds able to interact with these inflammatory mediators. The administration or stimulated production of anti-inflammatory mediators is considered an intriguing therapeutic possibility because of an imbalance between proinflammatory and anti-inflammatory mediators that might underlie chronic pulmonary inflammation [3].

Therapies affecting inflammatory mediators currently under investigation are: TNF- $\alpha$ inhibitors, chemokine inhibitors, NF$\kappa \mathrm{B}$ inhibitors, p38 mitogen-activated protein kinase (MAPK) inhibitors, phosphoinositide 3-kinase (PI3K) inhibitors, leukotriene $(\mathrm{LT}) \mathrm{B}_{4}$ inhibitors, peroxisome proliferator-activated receptors (PPARs) agonists, macrolides and statins (table 2).

\section{TNF- $\alpha$ inhibitors}

TNF- $\alpha$ is believed to play a central role in the pathophysiology of COPD [34]. It is produced by alveolar macrophages, neutrophils, T-cells, mast cells and epithelial cells following contact with different pollutants, including cigarette smoke. In animal models, TNF- $\alpha$ induces pathological features associated with COPD, such as an inflammatory cell infiltrate into the lungs, pulmonary fibrosis and emphysema. Moreover, it enhances neutrophil chemotaxis and migration by inducing the expression of chemokine CXCL8 (also known as IL-8) and upregulating endothelial adhesion molecules. In vivo, elevated levels of TNF- $\alpha$ have been demonstrated in peripheral blood, bronchial biopsies, induced sputum and bronchoalveolar lavage fluid of patients with stable COPD compared with control subjects. TNF- $\alpha$ together with IL-1 $\beta$ has been identified as a key cytokine that is able to initiate inflammatory cascades during exacerbations of COPD. In particular, it has been reported that TNF- $\alpha$ is the initial and predictive cytokine released in the cascade following exposure to lipopolysaccharide (LPS). It is therefore not surprising that it has been suggested that blocking the biological effects of TNF- $\alpha$ may be beneficial in the treatment of COPD.

There are three commercially available biologic agents that inhibit TNF- $\alpha$ : etanercept, infliximab and adalimumab. In addition, two other TNF inhibitors, certolizumab pegol and golimumab, are in development. They are effective in the treatment of inflammatory diseases, such as rheumatoid arthritis and inflammatory bowel disease, and their use could be extended to COPD. However, randomised controlled trials to evaluate the effectiveness of TNF- $\alpha$ inhibitors in patients with COPD have been few with the results of the first studies not being very promising [3537]. Moreover, higher incidence of pneumonia in infliximabtreated subjects and, although not statistically significant, more cases of cancer have been reported [36].

Nonetheless, an observational study conducted to evaluate the effectiveness of TNF- $\alpha$ antagonists in preventing COPD hospitalisations in a cohort of patients diagnosed with both rheumatoid arthritis and COPD identified from a health claims database, demonstrated that TNF- $\alpha$ inhibitors were associated with a reduction in the rate of COPD hospitalisation among patients with COPD receiving these agents to treat their rheumatoid arthritis [38]. This effect, however, was due exclusively to a reduction of $50 \%$ in the rate of COPD hospitalisation with etanercept, a fully human dimeric fusion protein composed of a TNF- $\alpha$ type II receptor and the Fc portion of immunoglobulin G1. The other TNF- $\alpha$ inhibitor under study, namely infliximab, did not reduce the risk of COPD hospitalisation.

It must be highlighted that the concentration of TNF- $\alpha$ in the blood or lungs of COPD patients is highly variable. Serum concentrations of TNF- $\alpha$ from the COPD patients in the 24 -week infliximab study were not particularly high [36], so it could be that this therapy would be effective in a subgroup of COPD patients where TNF- $\alpha$ is more abundant. We may also assume that TNF- $\alpha$ plays a prominent role in early disease, but less so in more advanced disease. In the infliximab study most of the patients were moderate to severe COPD patients [36] and this may also be a reason why there was no response to therapy.

In any case, TNF- $\alpha$ exists in two forms, the membrane-bound proform comprising 233 amino acids with a molecular mass of $26 \mathrm{kDa}$ and the soluble form of $17 \mathrm{kDa}$ comprising 157 nonglycosylated amino acids. It has been shown that the shredding of the biologically active TNF- $\alpha$ from its membraneanchored proform is mediated by a metalloproteinase called TNF- $\alpha$ converting enzyme (TACE) and inhibition of TACE blocks the release of TNF- $\alpha$ [3]. In an animal model of airway 


\section{TABLE 2 Inhibitors of inflammatory mediators}

Inhibitors

\section{Pros}

Cons

Drugs under development

TNF- $\alpha$ inhibitors

Chemokine inhibitors

NF-кB inhibitors They can efficiently inhibit the production of several proinflammatory cytokines

IKK2 inhibitors block LPS-induced lung neutrophilia in vivo
Effective inhibitors might cause immune suppression and impair host defences

Preliminary results negative

More COPD patients treated with TNF- $\alpha$ inhibitors developed cancers of the respiratory tract and severe lung infections
Inhibition of a single receptor or chemokine might not be sufficient to block the inflammatory response owing to the redundancy in the chemokine network

Undesired immunosuppression is the most worrying potential adverse effect

CXCR2 antagonists target only one of two CXCL8 receptors

CX3CL1 has a number of important physiological roles, including induction of antitumour activity and protection against neurodegenerative disorders CXCR3 is a difficult target (splice variants) Clinical studies are required

Effective inhibitors might cause immune suppression and impair host defences

These drugs have toxicity and side-effects so may only be suitable for topical application

Clinical studies are required p38 MAPK inhibitors
There is a much greater dependence on the p38 MAPK cascade in the neutrophil when compared with other leukocytes
Several reports have identified conditions in which p38 MAPK inhibitors enhance inflammatory responses
Humanised monoclonal antibodies to TNF- $\alpha$ Infliximab

Adalimumab

Certolizumab pegol

Golimumab

Humanised monoclonal antibodies to soluble TNF- $\alpha$ receptors

Etanercept

TACE inhibitors

PKF 242-484

PKF 241-466

Inhibitors of TNF- $\alpha$ production

Antisense oligonucleotides directed against the mRNA molecules encoding TNF- $\alpha$

Anti-CXCL8 mAb

$A B X-C X C L 8$

CXCR2 antagonists SCH527123

SB-656933

GSK-1325756

CCR2 antagonists INCB-8696

INCB-3284

INCB3344

NIBR-177

GSK-1344386B

CCX-140

JNJ-27553292

SKL-2841

BMS-741672

PF-04634817

CXCR3 antagonists

AMG-487 (T-487)

CX3CL1 antagonists

FKN-AT

F1

IKK inhibitors

IMD-0354

IMD-0560

BMS-345541

SC-514

ACHP

Bay 65-1942

AS602868

PS-1145

$\mathrm{NF}-\kappa \mathrm{B}$ "decoy" oligonucleotides

Antisense and small interfering RNA (siRNA) agents

Oral p38 MAPK inhibitors

SB 203580

SB 239063 


\section{TABLE 2 Continued}

\begin{tabular}{|c|c|c|c|}
\hline Inhibitors & Pros & Cons & Drugs under development \\
\hline $\begin{array}{l}\text { p38 MAPK } \\
\text { inhibitors (cont.) }\end{array}$ & $\begin{array}{l}\text { P38 MAPK inhibitors have been shown } \\
\text { to have efficacy in glucocorticoid-resistant } \\
\text { animal models of COPD }\end{array}$ & $\begin{array}{l}\text { p38 MAPK inhibitors have effects on various } \\
\text { cell types, thereby possibly enhancing the } \\
\text { therapeutic effects but also increasing } \\
\text { the risk of side-effects } \\
\text { These drugs should be delivered by } \\
\text { inhalation to reduce systemic exposure }\end{array}$ & $\begin{array}{l}\text { Doramapimod (BIRB 796) } \\
\text { SD282 } \\
\text { VX745 } \\
\text { SCIO469 } \\
\text { SD0006 } \\
\text { Dilmapimod } \\
\text { Losmapimod } \\
\text { CP690550 } \\
\text { PH797804 } \\
\text { BMS582949 } \\
\text { R1503 } \\
\text { AW814141 } \\
\text { Inhaled p38 MAPK inhibitors } \\
\text { ARRY371797 } \\
\text { PF03715455 } \\
\text { P38 MAPK antisense oligonucleotides } \\
\text { SCIO469 } \\
\text { SCIO323 }\end{array}$ \\
\hline PI3K inhibitors & $\begin{array}{l}\text { PI3K signalling cascade plays a pivotal role } \\
\text { in the activation of inflammatory cells }\end{array}$ & $\begin{array}{l}\text { Pan-isoform inhibitors of PI3K are likely } \\
\text { to be associated with side-effects, as } \\
\text { these enzymes appear to serve a } \\
\text { number of key cell functions } \\
\text { Clinical studies are required }\end{array}$ & $\begin{array}{l}\text { LY294002 } \\
\text { Small-molecule inhibitors of PI3K } \gamma \text { and } \delta \\
\text { TG100-115 } \\
\text { AS252424 } \\
\text { AS605240 }\end{array}$ \\
\hline LTB $_{4}$ inhibitors & $\begin{array}{l}\text { They might have some effect on sputum } \\
\text { neutrophil content and/or activation in } \\
\text { patients with stable COPD } \\
\text { They might protect the airways from } \\
\text { neutrophil-mediated damage and from } \\
\text { the effects of an acute exacerbation }\end{array}$ & 5-LO inhibitors induce side-effects & $\begin{array}{l}\text { BLT1 antagonists } \\
\text { LY } 29311 \\
\text { SB } 225002 \\
\text { SC } 53228 \\
\text { CP } 105696 \\
\text { Amelubant (BIIL284) } \\
\text { LY } 29311 \\
\text { LTB019 } \\
\text { SB } 201146 \\
\text { Dual BLT1 and BLT2 antagonists } \\
\text { RO5101576 } \\
\text { 5-LO inhibitors } \\
\text { Zileuton } \\
\text { MK-0633 } \\
\text { FLAP antagonist } \\
\text { BAYx1005 }\end{array}$ \\
\hline PPARs agonists & $\begin{array}{l}\text { Activation of PPAR } \gamma \text { and PPAR } \alpha \text { has } \\
\text { anti-inflammatory and immunomodulatory } \\
\text { effects } \\
\text { Activation of PPAR } \alpha \text { results in reduced } \\
\text { secretion of LTB } 4\end{array}$ & $\begin{array}{l}\text { Cardiovascular side-effects } \\
\text { with rosiglitazone } \\
\text { Clinical studies are required }\end{array}$ & $\begin{array}{l}\text { PPAR } \gamma \text { agonists } \\
\text { Troglitazone } \\
\text { Rosiglitazone } \\
\text { Pioglitazone } \\
\text { GW1929 } \\
\text { PPAR } \alpha \text { agonists } \\
\text { Clofibrate } \\
\text { Fenofibrate }\end{array}$ \\
\hline Macrolides & $\begin{array}{l}\text { Low-dose macrolides decrease the } \\
\text { production of proinflammatory cytokines } \\
\text { and chemokines by epithelial and immune } \\
\text { cells } \\
\text { Macrolides can exert therapeutic effects inde- } \\
\text { pendent of their antibacterial activity } \\
\text { Long-term low-dose macrolides reduce } \\
\text { exacerbation frequency }\end{array}$ & $\begin{array}{l}\text { Long-term low-dose macrolide treatment } \\
\text { is frequently associated with hearing } \\
\text { impairment } \\
\text { Chronic use can result in colonisation } \\
\text { of airways with macrolide-resistant bacteria } \\
\text { Clinical studies with immunolides are required }\end{array}$ & $\begin{array}{l}\text { Erythromycin } \\
\text { Clarithromycin } \\
\text { Roxithromycin } \\
\text { Azithromycin } \\
\text { Immunolides } \\
\text { EM703 } \\
\text { EM900 } \\
\text { CSY0073 } \\
\text { CEM-101 }\end{array}$ \\
\hline
\end{tabular}




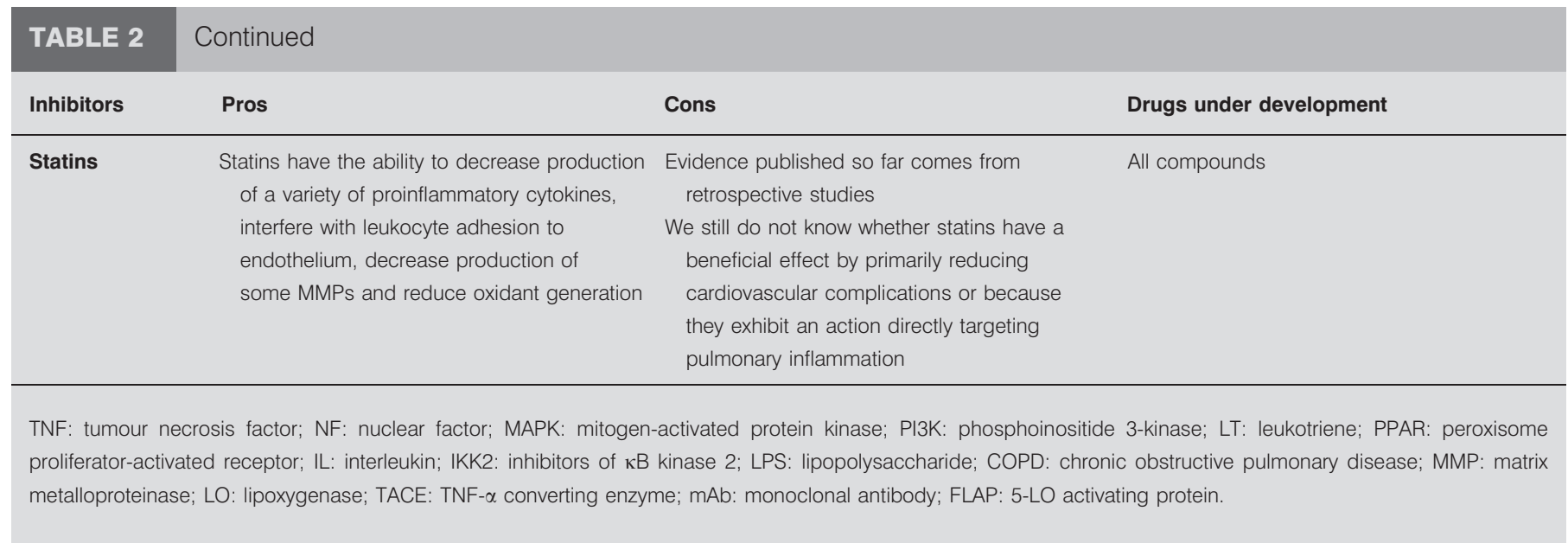

inflammation, PKF 242-484 and PKF 241-466, two TACE inhibitors, blocked TNF- $\alpha$ release into the airways and inflammatory cell influx [3]. So far no TACE inhibitor has reached the market. This has been attributed partially to the general lack of selectivity of TACE inhibitors [3].

The treatment of patients with inhibitors of TNF- $\alpha$ production, or with antisense oligonucleotides directed against the mRNA molecules encoding TNF- $\alpha$ might be alternative strategies to be explored [3].

\section{Chemokine inhibitors}

Inflammatory chemokines are produced during infection or tissue damage by a wide variety of cells, including resident and infiltrated leukocytes, in response to bacterial products and toxins or to inflammatory cytokines such as IL-1, TNF- $\alpha$ and interferons. They regulate increased inflammatory cell migration and activation in the lung. Chemokines are divided into four main classes based on the number and spacing of conserved cysteines at the amino terminus: CXC, CC, C and CX3C families. They signal through G-protein-coupled receptors.

ABX-CXCL8, an anti-CXCL8 mAb, was tested in a phase II trial of COPD, showing improvement in the transition dyspnoea index, but no improvement in lung function or health status of the treated patients [39]. ABX-CXCL8 only recognises free chemokine [40], but the active form of a chemokine is that which is bound to proteoglycans on the endothelial surface [41]. This could be a possible explanation for the clinical failure of this antibody.

Also in an attempt to overcome this problem, it has been suggested to therapeutically target the chemokine system by blocking the ligand-receptor interaction with antibodies or small molecular inhibitors to prevent the recruitment and activation of leukocytes induced by chemokines (fig. 2) [42]. However, one potential general challenge in targeting chemokines in COPD is the redundancy in the chemokine network such that inhibition of a single receptor or chemokine might not be sufficient to block the inflammatory response [43].

As several chemokines may activate a single receptor, their role is best discussed through their receptors, which are divided into receptors for CXC chemokines (CXCRs) and those for CC chemokines (CCRs) (table 2) [44].
CXCL8 activates neutrophils via a specific receptor (CXCR1) coupled to activation and degranulation, and via a high-affinity receptor (CXCR2), which is important in chemotaxis. In animal models of COPD, blockade of CXCR1 and CXCR2 by specific inhibitors significantly reduced neutrophilic airway inflammation [45]. CXCR2 antagonists are likely to be more useful because CXCR2 is also expressed on monocytes. Some CXCR2 antagonists are under development for the potential treatment of COPD (table 2). SCH527126 inhibited ozone-induced sputumderived neutrophilia in healthy volunteers [46], and SB-656933 blocked agonist-induced upregulation of CD11b on peripheral blood neutrophils of healthy subjects, an effect that correlates with inhibition of ozone-induced neutrophilia [47]. These findings are a sign of the potential of CXCR2 antagonists for treating patients with COPD. Nonetheless, the effects on many actions of CXCL8 and related chemokines acting upon CXCR2 must be monitored carefully as neutrophils are essential for host defence against microbial pathogens, and undesired immunosuppression is surely the most worrying potential adverse effect of administration of these compounds to humans [48].

Also CXCR3, another chemokine receptor whose expression is elevated in peripheral airways of smokers and patients with COPD [49], is a potential target for small-molecule antagonists

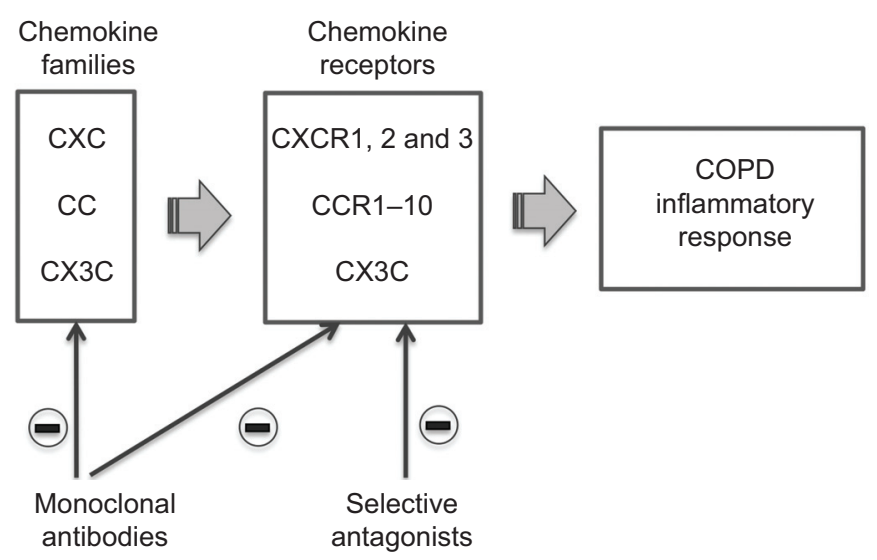

FIGURE 2. Schematic representation of chemokines and chemokine receptors that are potential targets for new drugs in patients with chronic obstructive pulmonary disease (COPD). 
or antibodies. The blockade of CXCR3 should prevent inflammatory cells from reaching sites of inflammation and thus alleviate the disease. Several small-molecule antagonists of CXCR3 have been reported (table 2).

CX3CL1, which exists as both a membrane-bound protein and a soluble chemokine, can mediate leukocyte adhesion and function as an effective chemoattractant [50]. It binds only to and is the unique ligand of $\mathrm{CX} 3 \mathrm{C}$ chemokine receptor 1 (CX3CR1). In a mouse model of smoking-induced emphysema, there is an influx of CX3CR1+ cells into the lung [51]. Moreover, the CX3CL1 expression is upregulated in the lung tissue of smokers with COPD [52]. This makes this ligand-receptor pair an attractive therapeutic target [53]. Antibodies or small molecules may be used to block the CX3CL1-CX3CR1 interaction (table 2). They may reduce or prevent leukocyte infiltration/accumulation, structural remodelling/destruction, and functional decline in the development and progression of COPD [54]. However, therapeutic development of CX3CR1 antagonists must be investigated cautiously because CX3CL1 has a number of important physiological roles, including induction of antitumour activity and protection against neurodegenerative disorders [54].

The action of CC-chemokines at the CCR2-receptor has also been shown to be involved in COPD [54]. Preclinical studies suggested that CCR2 plays an important role in the traffic of monocytes and macrophages towards sites of inflammation. Several selected CCR2 receptor antagonists and an anti-CCR2 mAb (MLN-1202) are under investigation (table 2); all demonstrate promising preclinical activity $[54,55]$. However, the low sequence homology of CCR2 and ligands between human and lower species means that one of the key questions is whether blocking CCR2 can generate sufficient clinical efficacy in patients with COPD [56].

\section{NF- $\kappa$ B inhibitors}

A large body of evidence has convincingly demonstrated a clear role for NF- $\mathrm{KB}$ transcription factors and their signalling kinases in both the stable and exacerbation forms of COPD (fig. 3) [57]. The inhibitor of NF- $\kappa \mathrm{B}(\mathrm{I} \kappa \mathrm{B})$ family of proteins regulates NF- $\kappa \mathrm{B}-$ dependent transcription by inhibiting DNA binding and localising these factors to the cell cytoplasm. IкB proteins are phosphorylated by IкB kinase complex consisting of at least three proteins, inhibitors of $\kappa B$ kinase (IKK) $\alpha, \operatorname{IKK} \beta$ and IKK $\gamma$. IKK $\alpha$ and IKK $\beta$ are two catalytic subunits, whereas IKK $\gamma$ is a regulatory subunit (NF-kB essential modulator; NEMO). Gene targeting experiments revealed that many proinflammatory stimuli required IKK $\beta$ subunit for NF-kB activation [58], while IKK $\alpha$ plays a role only in response to certain stimuli and in a limited number of cell types.

There are several possible approaches to the inhibition of NF-

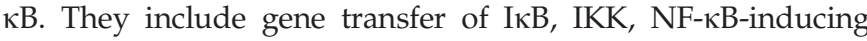
kinase and I $\mathrm{KB}$ ubiquitin ligase, which regulate the activity of $\mathrm{NF}-\kappa \mathrm{B}$ and drugs that inhibit the degradation of I $\mathrm{B}$ [59]. Several of these drugs are under development (table 2) [60]. BMS-345541 is a highly selective inhibitor of IKK with good pharmacokinetic characteristics (oral bioavailability 100\%, intravenous half-life 2.2 h). It inhibited TNF- $\alpha$-induced expression of IL-6, IL- 8 and eotaxin dose-dependently in the airway smooth muscle cells [61]. In human airway smooth muscle cells, co-incubation with BMS-345541 markedly inhibited the translocation of NF-kB to

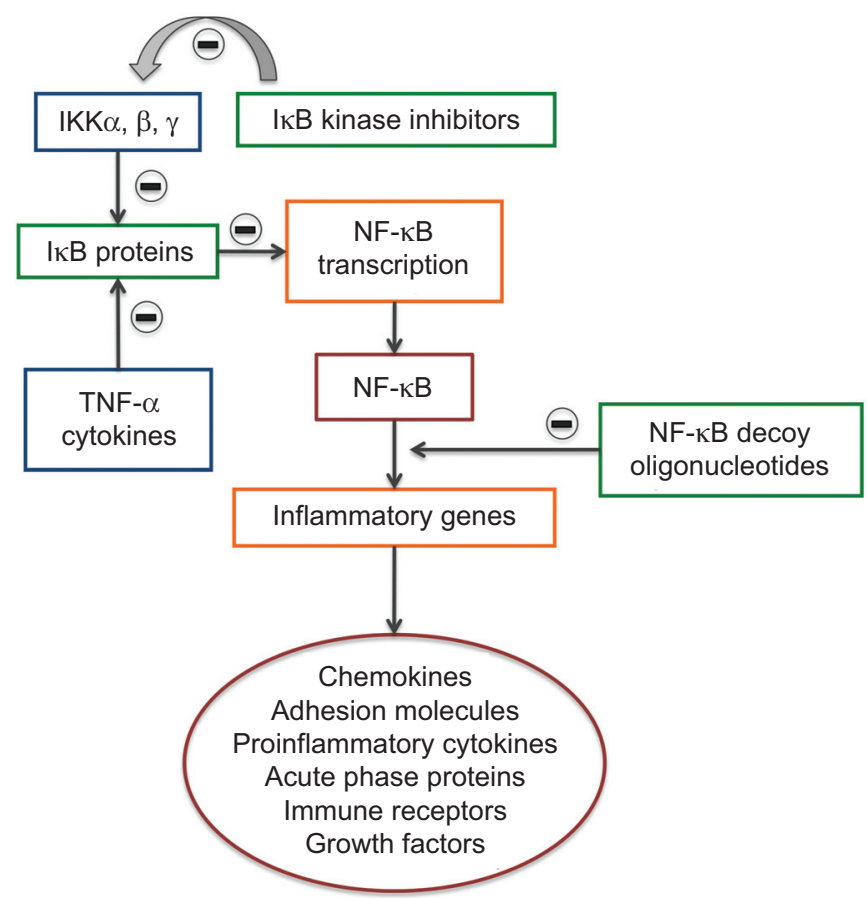

FIGURE 3. Canonical and non-canonical pathways of nuclear factor (NF)-kB

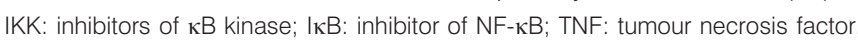

nuclei induced by TNF- $\alpha$ and IL-13 [62]. PS-1145 is able to induce a dose-dependent inhibition of phosphorylated IkB $\alpha$ and NF- $\kappa \mathrm{B}$ activation and, consequently, it reduces the expression of inflammatory factors including adhesion molecules, cytokines and chemokines on airway smooth muscle cells [63].

Further developments include NF-кB "decoy" oligonucleotides [64] and antisense and small interfering RNA (siRNA) agents [57]. "Decoy" oligonucleotides, in which double-stranded DNA oligonucleotides are used to act as decoys for transcription factors, competitively bind free NF- $\mathrm{BB}$ dimers thus preventing their interaction with cis-acting sites within promoter regions. Antisense agents use stabilised phosphothionate oligonucleotides to bind to complementary mRNA, thus blocking translation. siRNA agents are nucleic acid based that target the mRNA of NF$\kappa \mathrm{B}$ via the process of RNA interference and reduce its abundance.

One concern about long-term inhibition of NF- $\mathrm{kB}$, however, is that effective inhibitors might cause immune suppression and impair host defences. However, there are alternative pathways of NF-кB activation, via kinases other than IKK, which might be more important in regulating inflammatory disease [28].

\section{p38 MAPK inhibitors}

The MAPKs belong to serine/threonine kinase family that transduces environmental stimuli to the nucleus and control cell cycle machinery, cell death, gene transcription and protein translation. They play a key role in chronic inflammation. MAPKs are sequentially activated within a cascade of protein kinases and subdivided into three major pathways: extracellular signalregulated kinase (ERK), c-Jun N-terminal kinases (JNK)2, and p38 kinase [65]. The ERK pathway is stimulated in particular by G-protein coupled receptors and growth factors involved in cell proliferation, differentiation and survival, whereas JNK2 and p38 
are activated mainly by cytokines implicated in inflammation and apoptosis.

p38 MAPK seems to play a prominent role in COPD (fig. 4) [66]. Its activation in key inflammatory cell types correlates with disease initiation and progression [67]. p38 MAPK also appears to be the most effective MAPK in stabilising, at post-transcriptional level, the mRNAs for cytokines and chemokines relevant to COPD pathogenesis [68]. Four different isoforms of p38 MAPK are known, which are designated $\alpha, \beta, \gamma$ and $\delta$, respectively. p38 $\alpha$ is found as the predominant isoform in leukocytes, epithelial cells, smooth muscle cells, whereas p38 is more highly expressed in macrophages and p38 $\gamma$ in skeletal muscle [69].

Inhibition of p38 MAPK has thus attracted attention as a therapeutic target for the development of novel anti-inflammatory agents for the treatment of COPD (table 2) [70, 71]. Inhibitors that bind competitively at the ATP-binding pocket and target $\mathrm{p} 38 \alpha$ and $\beta$ but not $\delta$ or $\gamma$, potentially offer a broad range of anti-inflammatory effects because the $\alpha$ isoform is the most abundant isoform in inflammatory cells. They have shown efficacy in ameliorating several COPD-like pathologies in animal models [72].

In LPS and bleomycin models of inflammation and pulmonary fibrosis respectively, SB 239063 reduced neutrophil infiltration, IL-6 expression, and matrix metalloproteinase (MMP)-9 activity in the airways [72]. Another p38 MAPK inhibitor, doramapimod (BIRB 796) was shown to induce a dose-dependent inhibition on LPS-induced TNF- $\alpha$ production in human subjects, achieving 88 and $97 \%$ inhibition at doses of 50 and $600 \mathrm{mg}$, respectively [73], but dose-limiting liver toxicity prevents the use of higher doses [74]. Doramapimod is able to inhibit $\alpha, \beta$, and $\gamma$ isoforms, and also inhibits several non-p38 kinases [71].

Dilmapimod, which inhibited p-HSP27 and TNF- $\alpha$ production from whole blood obtained from patients with COPD [75], and PH797804, which reduced airway and systemic inflammatory responses induced by LPS inhalation in healthy subjects [76], have been tested in COPD patients. A 4-week treatment with dilmapimod elicited a reduction in sputum neutrophils and in serum fibrinogen, but not in serum CRP, IL-8, IL-1 $\beta$ or IL-6 levels; this was accompanied by an improvement in FVC but not

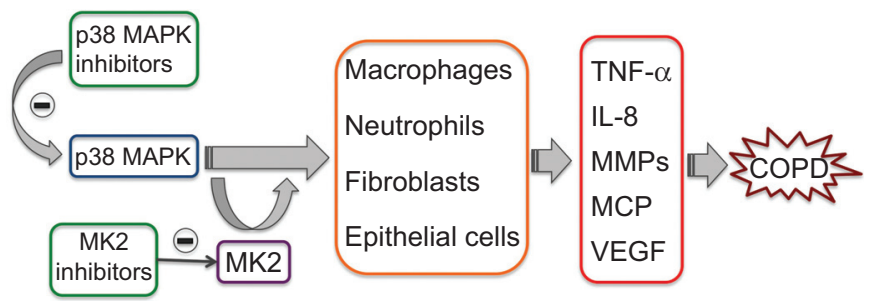

FIGURE 4. The p38 mitogen-activated protein kinase (MAPK) is expressed in the majority of inflammatory cells and regulates the production of key inflammatory mediators. Inhibition of p38 MAPK is expected to inhibit not only the production of proinflammatory cytokines but also their actions, thereby interrupting the vicious cycle that often occurs in chronic obstructive pulmonary disease (COPD). MK2, which is a downstream substrate of p38 MAPK, represents another excellent target for anti-inflammatory therapy. TNF: tumour necrosis factor; IL: interleukin; MMP: matrix metalloproteinase; MCP: monocyte chemotactic protein; VEGF: vascular endothelial growth factor. in FEV1 [77]. A 6-week treatment with PH797804 induced a significant increase of FEV1 and a concomitant improvement in dyspnoea score, inspiratory capacity and a sustained decrease in serum CRP levels after daily oral doses of 3, 6 and $10 \mathrm{mg} \cdot$ day $^{-1}$ for 6 weeks [78].

Nevertheless, the possibility of adverse events resulting from undesired pharmacological activity is a major concern for the p38 inhibitor drug class [79]. Moreover, there is concern about long-term use of p38 MAPK inhibitors because these inhibitors are effective suppressors of the innate immune response to viral and bacterial infections [80].

In order to decrease the risk of unwanted systemic side-effects, it has been suggested that a p38 MAPK inhibitors should be delivered directly into the lung [70, 81]. ARRY371797 and PF03715455 are potent and highly selective inhibitors of p38 MAPK both in vitro and in vivo. However, they are yet to be tested in patients with COPD. Also the p38 MAPK antisense oligonucleotides approach might have therapeutic potential for COPD but it has never been tested in COPD [3].

It must be highlighted that p38 $\alpha$ MAPK may not be an optimal target for the development of anti-inflammatory drugs because it participates in feedback control loops that suppress the activities of "upstream" MAPK kinase kinases (MAP3Ks), such as transforming growth factor-activated kinase-1 (TAK1) and mixed-lineage kinase (MLK)2/MLK3 that are implicated in the activation of other proinflammatory pathways, such as those leading to the activation of JNK2 and IKK $\beta$ [82]. Drugs that inhibit p38 $\alpha$ MAPK cancel these feedback control loops, leading to the hyperactivation of TAK1 and MLKs and hence the hyperactivation of JNK2.

\section{MK2 inhibitors}

MAPK-activated protein kinase 2 (MK2), a downstream substrate of p38 MAPK, is a more specific target that acts on limited downstream substrates (fig. 4), thus minimising its involvement with various mediators. Moreover, it plays multiple roles in the progression of inflammation and its inhibition is expected to produce the same beneficial effect as p38 MAPK inhibition, with lesser side-effects [83]. Even though MK2 inhibition is a promising target, many concerns have been raised because it is expressed in wide variety of cell and controls a vast array of functions. MK2 might also be activated by signalling cascades other than the p38 pathway and its inhibition could give rise to some undesirable side-effects [83].

\section{PI3K inhibitors}

PI3K catalyses the production of phosphatidylinositol-3,4,5triphosphate $\left(\mathrm{PI}(3,4,5) \mathrm{P}_{3}\right)$, an important second messenger in signal transduction, and initiates several cytosolic events leading to cell growth, entry into the cell cycle, cell migration and cell survival [84]. Several of these events are proinflammatory. PI3K is important in the activation of macrophage and neutrophils [85] and its function may be altered in COPD [86]. Therefore, PI3K inhibition has been suggested as a novel therapeutic strategy for COPD.

The PI3K family are divided into three subtypes (class I, II and III), based on their structure, phospholipid substrate and mode of regulation [87]. Class I enzymes play important roles in many steps of the inflammatory reaction (fig. 5). The class I PI3Ks can 


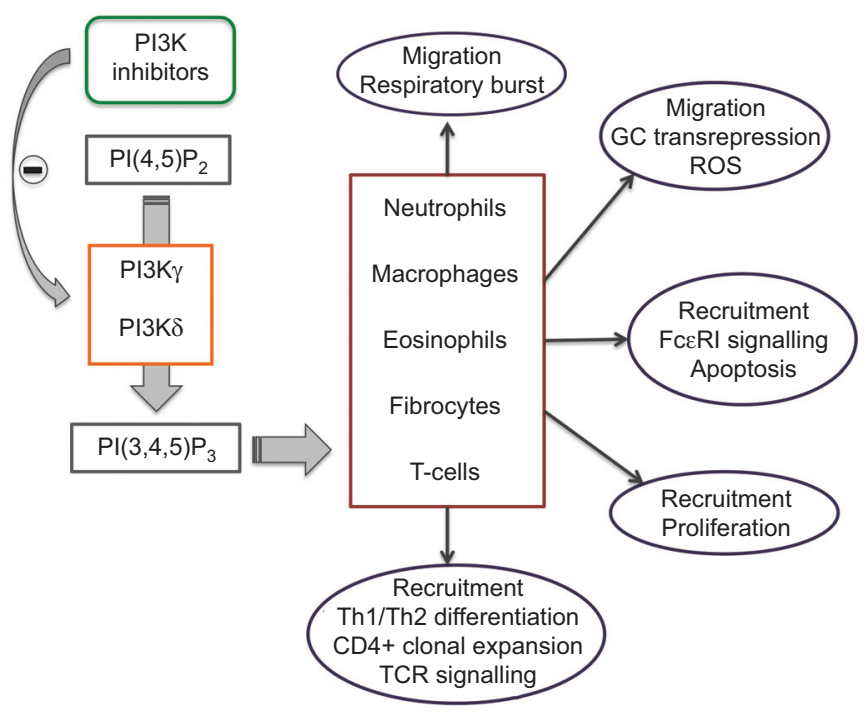

FIGURE 5. Schematic representation of the roles of phosphoinositide 3-kinase $(\mathrm{PI} 3 \mathrm{~K}) \delta$ and $\mathrm{PI} 3 \mathrm{~K} \gamma$ signalling in selected cells important in respiratory disease. TCR: T-cell receptor; ROS: reactive oxygen species; GC: glucocorticoid.

be further subtyped depending on their associated catalytic subunit into class IA and class IB. In mammals, class IA includes three different isoforms: $\mathrm{PI} 3 \mathrm{~K} \alpha, \mathrm{PI} 3 \mathrm{~K} \beta$ and PI3K $\delta$. Class IB is constituted by one isoform, PI3K $\gamma$, which acts downstream of $\mathrm{G}$ protein-coupled receptors, such as receptors for chemokines. Both PI3K $\gamma$ and PI3K $\delta$ are expressed predominantly (but not exclusively) in leukocytes, leading to speculation that they are the dominant isoforms involved in PI3K-mediated signalling of both the innate and adaptive immune responses, although recently it has been suggested that PI3K $\beta$ plays a critical role in neutrophil activation by immune complexes [88].

Some small-molecule inhibitors of PI3K $\gamma$ and $\delta$ are in development (table 2) [89]. Aerolised TG100-115, a double-selective compound blocking both PI3K $\gamma$ and PI $3 \mathrm{~K} \delta$, inhibited pulmonary neutrophilia induced by both intranasal LPS and smoke exposure in a murine COPD model [90]. AS605240, a PI3K $\gamma$-selective inhibitor, reduced polymorphonuclear leukocyte migration in vitro and polymorphonuclear leukocyte infiltration into the lung in vivo in a murine model of LPS-induced lung injury [91]. Interestingly, interventional treatment with TG100-115 was successful even in a steroid-resistant form of COPD, induced in mice by cigarette smoke exposure [90].

Nonetheless, animals devoid of functional PI3K $\gamma$ activity display a reduced host response to Streptococcus pneumoniae [92], a finding that questions the importance of PI3K inhibitors in COPD.

\section{$\operatorname{LTB}_{4}$ inhibitors}

$\mathrm{LTB}_{4}$ contributes to neutrophil chemotaxis [93]. Moreover, it induces retardation of neutrophil apoptosis [93]. Consequently, antagonism of $\mathrm{LTB}_{4}$ receptors is also being considered as a potential treatment of COPD (table 2).

The effects of $\mathrm{LTB}_{4}$ are mediated by two G-protein-coupled receptors termed BLT1 and BLT2 [94]. Classically, BLT1 mediates $\mathrm{LTB}_{4}$-evoked neutrophil and macrophage migration to sites of inflammation via chemotaxis and upregulation of adhesion molecules (e.g. Mac-1). Clinically, $\mathrm{LTB}_{4}$ has been shown to be the major neutrophil chemoattractant in exhaled breath condensate and sputum from COPD patients and to promote survival of neutrophils via BLT1 receptor activation [95]. Also BLT2 is expressed on neutrophils and macrophages and 15hydroxyeicosatetraenoic acid, a ligand for BLT2, has been shown to be increased in patients with chronic bronchitis and to play a role in modulation of $\mathrm{LTB}_{4}$ levels and neutrophil chemotaxis [96]. In addition to BLT1 and BLT2, $\mathrm{LTB}_{4}$ binds and activates the PPAR $\alpha$. Activation of this receptor results in several antiinflammatory effects, thus it has been suggested that responses to $\mathrm{LTB}_{4}$ could represent an integration of proinflammatory and anti-inflammatory effects, mediated by cell surface and nuclear receptors, respectively [97].

Several BLT1 antagonists have now been developed for the treatment of neutrophilic inflammation [3, 94]. However, so far clinical studies in COPD have been negative [98] and, generally, they have not been published. Interestingly, also the dual BLT1 and BLT2 receptor antagonism had no effects on LPS-evoked neutrophilia in guinea pigs and cigarette smoke-evoked neutrophilia in mice and rats [99].

Another potential approach is to prevent the synthesis of $\mathrm{LTB}_{4}$. The 5-lipoxygenase (LO) inhibitor, 5-LO activating protein (FLAP) inhibitor, and dual 5-LO/cyclooxygenase inhibitor classes inhibit neutrophil influx and tissue oedema when administered orally to animals, probably because of a reduction in tissue $\mathrm{LTB}_{4}$ levels and $\mathrm{LTB}_{4}$ synthesis [100]. In a trial of eight patients with COPD, the 5LO inhibitor zileuton significantly improved exercise capacity as measured by the 6-min walk test compared with placebo, as well as quality of life and COPD questionnaire scores [101]. A small study suggested that a FLAP antagonist, BAYx1005, can produce modest reductions in some measures of neutrophilic bronchial inflammation in patients with COPD, but spirometric end-points such as FEV1 were not reported [102]. However, in a recent phase IIa proof-of-concept study, MK-0633, a 5-LO inhibitor, was not significantly more effective than placebo in improving pre-dose, pre-bronchodilator FEV1 from baseline after 12 weeks of treatment in patients with COPD [103]. The incidence of adverse effects is, in any case, limiting the development of 5-LO inhibitors [100], although recently it was documented that zileuton during COPD exacerbations that required hospital admission was safe and reduces urinary $\mathrm{LTE}_{4}$ levels, but there was no evidence suggesting that this intervention shortened hospital stay [104].

\section{PPAR agonists}

PPARs are ligand-activated nuclear hormone receptors belonging to the steroid receptor superfamily. Originally identified for their role in lipid and glucose regulation, PPARs have more recently been implicated in the regulation of other phenomena, including inflammation [105]. In particular, PPARs have been demonstrated to be involved in the modulation of NF- $\mathrm{kB}$ transcriptional activity [106]. The transrepressive effects of PPARs are indirect in the sense that they involve the interference with transcriptions factor complexes that regulate inflammatory gene programmes [106].

The three recognised subtypes, PPAR $\alpha$ (also known as NR1C3), PPAR $\gamma$ (NR1C1) and PPAR $\delta$ ( $\beta$ or NR1C2), are widely expressed [105]. There is evidence that activation of PPAR $\gamma$ and PPAR $\alpha$ 
may have anti-inflammatory and immunomodulatory effects [105]. As already mentioned, $\mathrm{LTB}_{4}$ directly activates PPAR $\alpha$ [97], but it has also been documented that activation of PPAR $\alpha$ results in reduced secretion of $\mathrm{LTB}_{4}$ [106]. This finding suggests an important homeostatic mechanism by which a crucial proinflammatory mediator ultimately limits its own activity and thus facilitates resolution of the inflammatory process [107].

PPAR $\gamma$ agonists, such as troglitazone and rosiglitazone, which are thiazolidinediones, inhibit the release of inflammatory cytokines from monocytes and induce apoptosis of T-lymphocytes, suggesting that they may have anti-inflammatory effects in COPD [108]. In an animal model of COPD-like airway inflammation the PPAR $\gamma$ agonist, rosiglitazone, inhibits LPSinduced neutrophilia and reduces chemoattractants and survival factors [105]. However, in vitro research has documented that only large doses of thiazolidinediones produce anti-inflammatory effects, leading to questions about the relevance of PPAR $\gamma$ stimulation in COPD [105]. In any case, these large doses might enable thiazolidinediones to act by non-PPAR $\gamma$-related mechanisms. PPAR $\gamma$ agonists also inhibit lung fibrosis and therefore have the potential to prevent progression of small airway fibrosis in COPD [109]. Unfortunately, a problem which may hamper this strategy has been the suggestion of an association of rosiglitazone treatment with an increased risk of cardiovascular events in patients being treated for type 2 diabetes [110].

In order to decrease the potential cardiovascular risk of thiazolidinediones, non-thiazolidinedione PPAR $\gamma$ ligands are in preclinical evaluation. GW1929 displays anti-inflammatory in poly(I:C)-induced air-liquid interface human bronchial epithelial cells similar to that induced by troglitazone [111].

Finally, given that reduced PPAR $\alpha$ expression is correlated with cachexia and systemic inflammation, it has been suggested that PPAR $\alpha$ agonists, such as clofibrate and fenofibrate, may have therapeutic potential in treating the systemic features of COPD [112].

\section{Macrolides}

Macrolides elicit anti-inflammatory effects that may be independent of their antibiotic effects [113]. They modulate inflammatory and immune responses without affecting homeostatic immunity [114, 115].

In the setting of chronic inflammation, low-dose macrolides decrease the production of proinflammatory cytokines and chemokines by epithelial and immune cells [113-115]. These activities are inhibitory in nature and extend to the modulation of adhesion molecules essential to the process of recruiting neutrophils at the site of inflammation [116]. There is robust evidence linking these effects to interference with the signalling pathways mediated by activator protein-1, ERK1/2 and NF-кB [116].

Macrolides possess the ability to modulate the release of proinflammatory mediators from epithelial cells in response to virus [117] and cause a significant reduction in the chemotactic response of neutrophils to chemokines [118]. Animal models provided further evidence that macrolides may block the proinflammatory actions of LPS on the airway [119] and ameliorate emphysema induced by cigarette smoke in mice in a manner that is independent of antibiotic effects [120].

Macrolide therapy induces a decrease in airway neutrophilia in a variety of conditions [121]. In COPD, the overall profile of inhibition of inflammatory mediator production by COPD sputum cells appears to be qualitatively and quantitatively broader than that of glucocorticoids, p38 MAPK inhibitors and PDE4 inhibitors [122].

Some studies suggested an effect of long-term macrolide therapy on the frequency of exacerbations or common colds in patients with COPD $[123,124]$, although this ability would seem to be additive to other conventional therapies, such as inhaled glucocorticoids with or without long-acting $\beta_{2}$-agonists or longacting muscarinic antagonists. Whether this occurs because of antimicrobial activity, immunomodulation, or both, remains to be determined.

Macrolide derivatives with anti-inflammatory activity but lacking antibacterial activity would be extremely useful, as they would help avoid promotion of drug resistance. Several nonantibiotic macrolides, which can also be called immunolides, are now in development as anti-inflammatory therapies (table 2) [125].

\section{Statins}

Statins are 3-hydroxy 3-methylglutaryl coenzyme A (HMG-CoA) reductase inhibitors and for this property they are currently widely used as cholesterol-lowering agents. Recently, statins have received increasing interest also for their anti-inflammatory effect [126]. They have the ability to decrease production of a variety of proinflammatory cytokines [127], and also interfere with leukocyte adhesion to endothelium [128], effects that would prevent leukocyte egress into the lung parenchyma. Interestingly, statins decrease production of some matrix metalloproteases, notably MMP-1, MMP-2 and MMP-9 [129]. They also reduce oxidant generation [129]. Statins have been shown to modify airway inflammation in animal models and matrix remodelling, notably inhibiting emphysema formation [129].

These effects might explain why uncontrolled observational studies have suggested that statins diminish the decline in pulmonary function of smokers and former smokers and decrease the risk of emergency treatment and hospitalisation in COPD patients, reducing also morbidity and mortality in COPD [130, 131]. Therefore, statins are emerging as effective therapies in COPD management. All published reports support a possible beneficial role for these agents in the treatment of COPD, but they need to be confirmed by randomised controlled trials, such as the National Heart, Lung, and Blood Institutesponsored ongoing trial by the COPD Clinical Research Network, STATCOPE, that will carefully weigh the benefits and risks of a once-daily dose of statin in a 3-yr study of over 1,000 COPD patients. Nonetheless, a recent prospective study has indicated that the use of statins in patients hospitalised for an exacerbation of COPD was associated with a lower risk for subsequent exacerbation of COPD and severe exacerbation of COPD [132]. Whether statins have a beneficial effect in COPD patients by primarily reducing cardiovascular complications or because they exhibit an action directly targeting pulmonary inflammation is, however, a matter of controversy [131].

\section{DRUGS THAT MAY HAVE INDIRECT ANTI- INFLAMMATORY ACTIONS}

Some drugs used in the treatment of COPD are not antiinflammatory agents themselves, but can elicit an important indirect anti-inflammatory action (table 3). 
TABLE 3 Drugs that may have indirect anti-inflammatory actions

Drug Pros Con

Cons

Drugs under development

\section{Agents that reverse glucocorticoid resistance}

Bronchodilators

Antioxidant
strategies
Potent mucolytic
Mild effects on exacerbation rates
Nrf2 activators
Protection seen in animal models
Induce a variety of phase II
genes/enzymes
SOD mimetics
Protection seen in animal models
Inhibit extracellular matrix remodelling
Lipid peroxidation and protein carbonylation
inhibitors/blockers
Inhibit lipid peroxidation chain reactions

Protease inhibitors

Most MMP inhibitors prevented emphysema and small airways thickening in preclinical models of COPD
Clinical studies are required resistance by blocking the underlying mechanisms

Bronchodilators have the potential to reduce inflammation by decreasing dynamic hyperinflation and influencing resistive breathing

Low-dose theophylline has antiinflammatory effects inflammatory effect
Studies on the effect of $\beta_{2}$-agonists on contractility of the diaphragm are controversial

Tiotropium reduces lung hyperinflation but has not convincingly demonstrated an anti-

There is no documentation that antiinflammatory effects of theophylline are due to a decrease in loaded breathing

\section{Thiol compounds}

Lack of bioavailability

Cause bronchoconstriction

Nrf2 activators

Dramatically degraded in severe COPD

GOLD stages

Carbonylation/oxidation of Nrf2/Keap1

Prophylactic-potent inducer is needed

Clinical studies are required

SOD mimetics

May impair phagocytosis

Alter endogenous redox homeostasis

Clinical studies are required

Lipid peroxidation and protein carbonylation inhibitors/blockers

Poor bioavailability

Low presence at the site of microenvironment

Clinical studies are required

\section{Activation of HDAC2 \\ Theophylline \\ Curcumin \\ Resveratrol}

Inhibitors of P-glycoprotein

Inhibitors of MIF

$\beta_{2}$-agonists

Long-acting antimuscarinic agents

Methylxanthines

Thiol compounds

$\mathrm{N}$-acetyl-L-cysteine (NAC)

$\mathrm{N}$-acystelyn (NAL)

$\mathrm{N}$-isobutyrylcysteine (NIC)

Glutathione esters

S-carboxymethylcysteine (carbocysteine)

Erdosteine

Fudosteine

Thioredoxin

Procysteine

Ergothioneine

Inducers of glutathione biosynthesis (Nrf2 activators)

Antioxidant vitamins (vitamin A, E, C) $\beta$-carotene

$\mathrm{CoQ}_{10}$

Polyphenols

Curcumin

Resveratrol

Quercetin

Green tea catechins

Nitrone spin traps

NXY-059

STANZ

Porphyrins

SOD and glutathione peroxidase mimetics

M40419, M 40403, M40419

Ebselen

Lipid peroxidation and protein carbonylation inhibitors/blockers Edaravone

Lazaroids

Clinical development has been stopped for many MMP and NE inhibitors for various reasons

\section{MMP inhibitors}

Tissue inhibitors of metalloproteases Antibiotics 


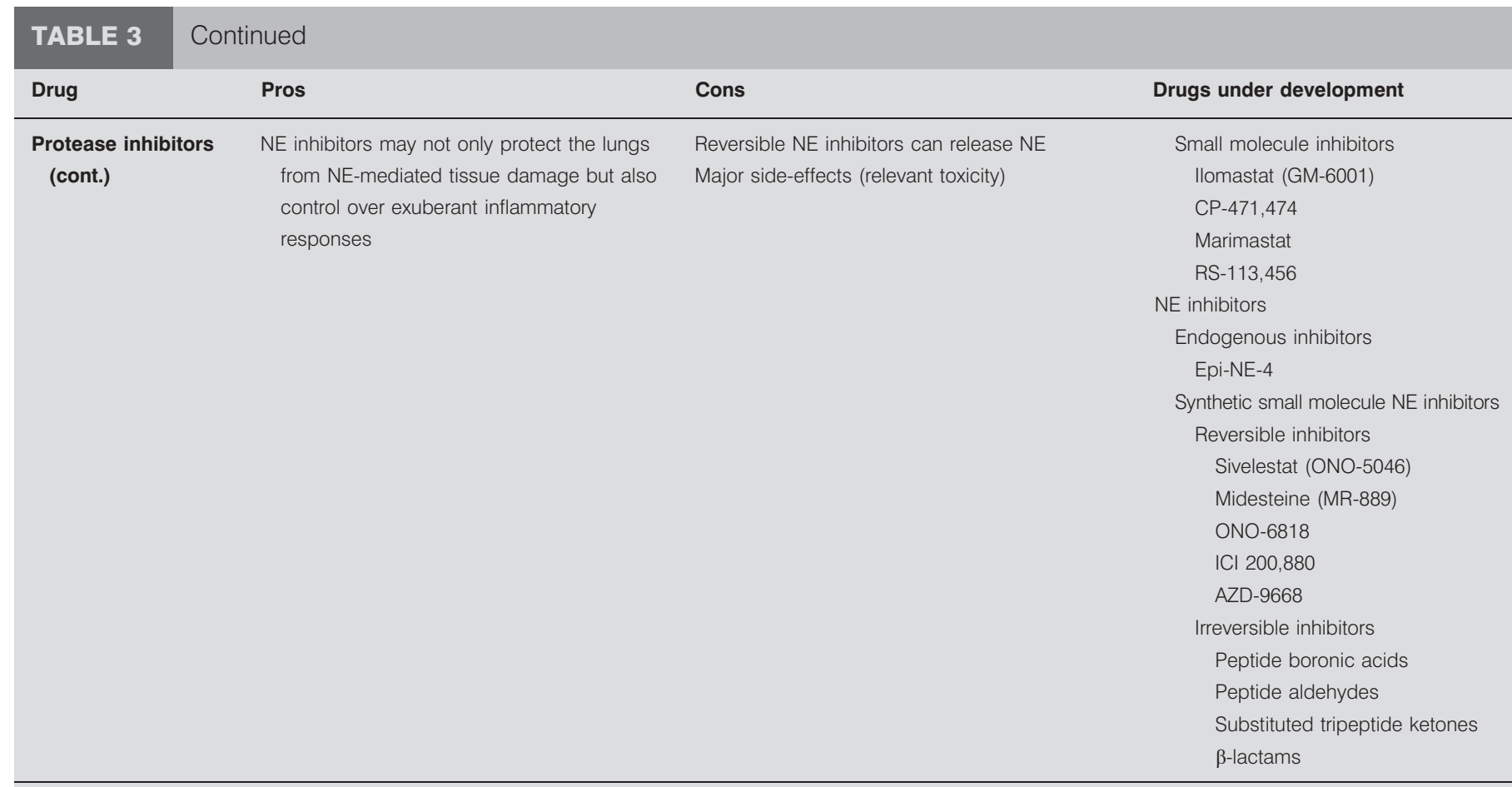

SOD: superoxide dismutase; MMP: matrix metalloproteinase; COPD: chronic obstructive pulmonary disease; NE: neutrophil elastase; GOLD: Global Initiative for Chronic Obstructive Lung Disease; MIF: migration inhibitory factor.

\section{Reversing glucocorticoid resistance}

As already mentioned, it has now been accepted that inflammation in patients with COPD is at least partly glucocorticoidresistant, in a large part because cigarette smoking and oxidative stress impair HDAC2 function [2]. Glucocorticoids suppress multiple inflammatory genes that are activated in chronic inflammatory diseases by reversing histone acetylation of activated inflammatory genes through binding of liganded glucocorticoid receptors to coactivator molecules and recruitment of HDAC2 to the activated transcription complex. In COPD, HDAC2 is markedly reduced in activity and expression as a result of oxidative/nitrative stress so that inflammation becomes resistant to the anti-inflammatory actions of glucocorticoids [133].

In patients with glucocorticoid resistance, drugs that may reverse the molecular mechanism of glucocorticoid resistance are being investigated (fig. 6) [133]. Selective activation of HDAC2 can be achieved with theophylline, which restores HDAC2 activity in COPD macrophages back to normal and reverses glucocorticoid resistance. The molecular mechanism of action of theophylline in restoring HDAC2 appears to be via selective inhibition of $\mathrm{PI} 3 \mathrm{~K} \delta$, which is activated by oxidative stress in COPD patients [133]. This suggests that selective PI3K $\delta$ inhibitors may also be effective. Since oxidative stress appears to be an important mechanism in reducing HDAC2 and leads to glucocorticoid resistance, antioxidants should also be effective [133]. Similar to theophylline, the naturally occurring polyphenols, such as curcumin and resveratrol that are dietary antioxidants, mediate restoration of glucocorticoid function through a protection of HDAC2 expression and activity [134].
There is increasing evidence that the activity of membrane transporters such as P-glycoprotein (P-gp), a transmembrane protein that extrudes glucocorticoids from cells, may influence the intracellular concentrations of glucocorticoids [135]. It has been suggested that high levels of expression of MDR1, the multidrug-resistance gene that encodes P-gp, might be implicated as a mechanism for glucocorticoid resistance in inflammatory diseases [133]. There are several therapeutic strategies for inhibiting P-gp to prevent the efflux of glucocorticoids, some of which are based on the observations that verapamil and quinidine are efflux blockers; several novel drugs are now in development for this purpose [136].

In addition, increased macrophage migration inhibitory factor (MIF), a proinflammatory cytokine that has potent anti-glucocorticoid effects, has been implicated in glucocorticoid resistance, so strategies to inhibit MIF, including small molecule inhibitors and monoclonal antibodies, are currently being explored [137].

\section{Bronchodilators}

Loaded breathing initiates an inflammatory response consisting of elevation of plasma cytokines that are produced within the diaphragm as a result of increased muscle activation and recruitment and activation of lymphocyte subpopulations [138]. These cytokines might mediate the diaphragm muscle injury and also compromise diaphragmatic contractility and contribute to the development of muscle cachexia. In addition, they might have systemic effects, mobilising glucose from the liver and free fatty acids from the adipose tissue to the strenuously working respiratory muscles [138]. It has been suggested that bronchodilators 


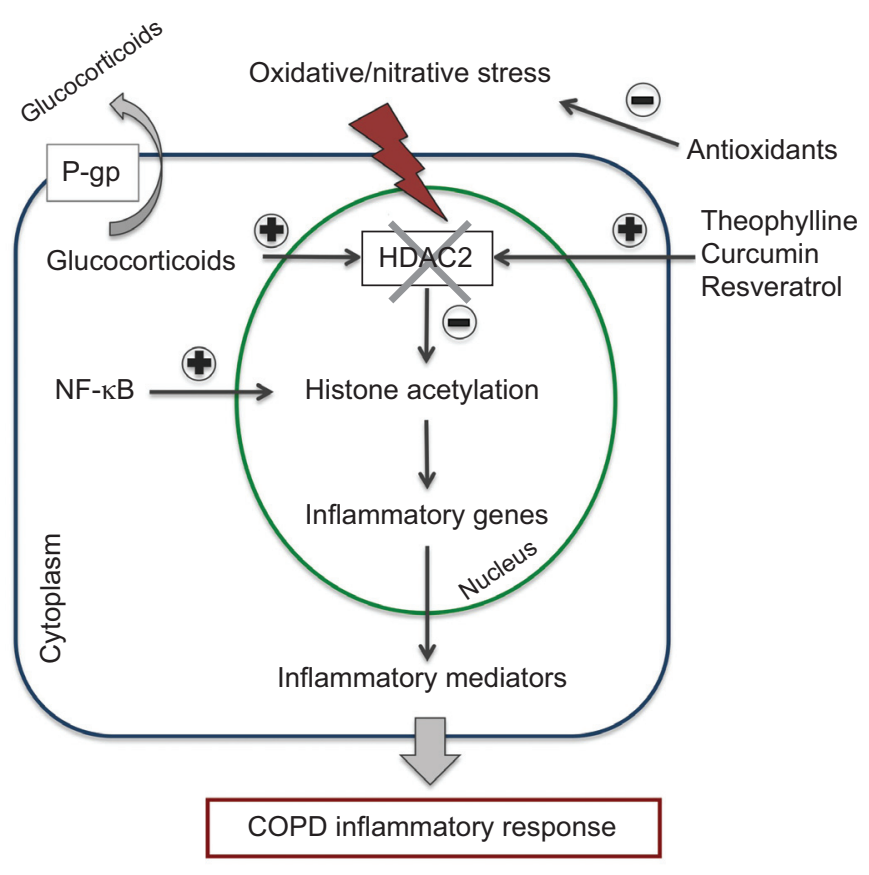

FIGURE 6. In chronic obstructive pulmonary disease (COPD) patients, chronic oxidative stress activates macrophages and impairs HDAC2 activity. Loss of HDAC2 function leads to enhanced inflammatory gene expression and glucocorticoid resistance. Moreover, there is increasing evidence that the activity of membrane transporters such as P-glycoprotein (P-gp) may influence the intracellular concentrations of glucocorticoids. P-gp extrudes glucocorticoids from cells, thereby lowering their intracellular concentration. Several drugs may reverse the molecular mechanism of glucocorticoid resistance by restoring HDAC2 activity or inhibiting P-gp. NF-kB: nuclear factor- $\mathrm{kB}$

have the potential to reduce inflammation by decreasing dynamic hyperinflation and influencing resistive breathing [138].

Unfortunately, studies on the effect of $\beta_{2}$-agonists on contractility of the diaphragm have produced controversial results [139, 140]. Moreover, although tiotropium, a long-acting antimuscarinic agent, can sustain significant reductions in lung hyperinflation and, consequently, reduces loaded breathing [141], clinical trials with this agent have not convincingly demonstrated an antiinflammatory effect [142]. Also, studies examining the muscle inotropic effects of the methylxanthines offer some contradictions. Aminophylline increases diaphragmatic contractility, reversing diaphragm fatigue [143] and, moreover, low-dose theophylline has anti-inflammatory effects in COPD [144]. However, these effects have not been observed by all investigators, and there are doubts that they are due to a decrease in loaded breathing [144]. These findings question the importance of bronchodilators in reducing inflammation caused by loaded breathing.

\section{Antioxidant strategies}

Cigarette/tobacco smoke/biomass fuel-induced oxidative and aldehyde/carbonyl stress are intimately associated with inflammation in COPD. Consequently, agents that can suppress either the generation of reactive oxygen species or can neutralise such species or both have the potential of indirectly influencing inflammation [145].
Among the various antioxidants tried so far, thiol antioxidants and mucolytic agents, and dietary polyphenols have been reported to increase intracellular thiol status along with induction of glutathione biosynthesis. Such an elevation in the thiol status in turn leads to detoxification of free radicals and oxidants as well as inhibition of ongoing inflammatory responses. Inducers of glutathione biosynthesis (Nrf2 activators), antioxidant vitamins, spin traps, superoxide dismutase and glutathione peroxidase mimetics, and lipid peroxidation and protein carbonylation inhibitors/blockers have also been shown to have beneficial effects by inhibiting cigarette smoke-induced inflammatory responses and other carbonyl/oxidative stress-induced cellular alterations (table 3) [145].

Since a variety of oxidants, free radicals and aldehydes are implicated in the pathogenesis of COPD, the effects of a combination of various antioxidants along with thiols, spin traps, lipid peroxidation/protein carbonylation inhibitors/blockers, or enzyme mimetics is an interesting proposition worth investigating in patients with COPD. Antioxidants (e.g. thiols and other molecules) may be combined with anti-inflammatories/PDE4 inhibitor/Sirtuin1 activator, bronchodilators, steroids, antibiotics, and statins [145].

\section{Protease inhibitors}

Neutrophils, macrophages and cytotoxic T-lymphocytes release an array of proteolytic enzymes, including serine (elastase, proteinase 3), cysteine (cathepsin S) and metallo-(MMP-12) proteases. These proteinases cleave components of the extracellular matrix, elastin fibres and collagen, generating elastin fragments or collagen-derived peptides such as proline-glycineproline, which have been shown to be chemotactic for monocytes, the precursor cell for macrophages or neutrophils [146].

The steps of the proteolytic cascade present multiple potential targets for therapeutic intervention [147]. New compounds have been developed to antagonise each of these steps (table 3). Collagen and elastin processing each feature MMPs as active proteases. Nonspecific MMP inhibitors such as ilomastat (GM-6001), marimastat, RS-113,456 or CP-471,474 can therefore suppress the proinflammatory signalling caused by collagen or elastin degradation (table 3). Furthermore, specific antagonists of either collagen or elastin breakdown have shown promise in preclinical work.

A number of synthetic neutrophil elastase (NE) inhibitors have been developed as potential therapeutic agents (table 3) [148]. These include irreversible inhibitors and reversible inhibitors. One of the problems with the low molecular weight reversible inhibitors is that they can release NE, allowing it to destroy tissue. Although irreversible inhibitors have been shown to function effectively in vivo in hamsters to reduce many of the effects of intratracheally administered NE, their toxicity prevents clinical use. Sivelestat, which is marketed in Japan and Korea for the treatment of acute lung injury associated with systemic inflammatory response syndrome, and ONO-6818 have been developed and have seen mixed results in human studies, while other NE inhibitors in preclinical or phase I trials were discontinued for various reasons [149]. Interestingly, 3 months of treatment with AZD9668 did not improve lung function, respiratory signs and symptoms or quality of life score when added to budesonide/ formoterol maintenance therapy in patients with COPD [150]. 
The lack of effect of NE inhibitors in COPD may be because the role of neutrophils in the pathogenesis of COPD is less significant than previously thought [150]. Alternatively, the addition of a NE inhibitor may result in no further benefit in addition to that already gained with conventional maintenance therapy.

\section{CONCLUSION}

In the 2004, American Thoracic Society/European Respiratory Society guidelines [151] identified a pressing need to develop agents that suppress the inflammation associated with COPD and prevent disease progression. In these past years, several new potential targets have been identified and novel agents for these new targets, as well for known targets have been developed. These interventions have been effective in animal models, but translation to humans has not been straightforward and there is a major discrepancy between the animal data and human trials [152].

A possible explanation for the apparent limited efficacy of antiinflammatory therapy in COPD is that by the time COPD has become clinically apparent, the disease is already moderately advanced, with irreversible parenchymal damage, thus limiting the benefits of anti-inflammatory treatments alone, particularly with respect to lung function [113]. Therefore, the reason for the discrepancy between the animal data and human trials probably relates, in a large part, to the inability to produce severe COPD in laboratory animals. Moreover, the full development of novel anti-inflammatory agents might be problematic because the currently used clinical assessments of patients with COPD are not indicative of the inflammatory process [153].

For these reasons, it is not surprising that only one drug, roflumilast, an orally active PDE4 inhibitor, has reached the market for the treatment of COPD, while all the other new pharmacological anti-inflammatory approaches tested in humans have been found ineffective or burdened by major side-effects. It is clear that, despite the advances made in this area, there are still significant gaps in our understanding. What we have really understood is that the development of novel treatments for COPD, other than bronchodilators, remains a challenge.

\section{STATEMENT OF INTEREST}

None declared.

\section{REFERENCES}

1 Brusselle GG, Joos GF, Bracke KR. New insights into the immunology of chronic obstructive pulmonary disease. Lancet 2011; 378: 1015-1026.

2 Barnes PJ. Corticosteroid resistance in airway disease. Proc Am Thorac Soc 2004; 1: 264-268.

3 Matera MG, Cazzola M. New anti-inflammatory approaches in COPD. Drug Discov Today: Ther Strat 2004; 1: 335-343.

4 Spina D. Phosphodiesterase-4 inhibitors in the treatment of inflammatory lung disease. Drugs 2003; 63: 2575-2594.

5 Martorana PA, Beume R, Lucattelli M, et al. Roflumilast fully prevents emphysema in mice chronically exposed to cigarette smoke. Am J Respir Crit Care Med 2005; 172: 848-853.

6 Boswell-Smith V, Cazzola M, Page CP. Are phosphodiesterase 4 inhibitors just more theophylline? J Allergy Clin Immunol 2006; 117: $1237-1243$

7 Calverley PM, Rabe KF, Goehring UM, et al. Roflumilast in symptomatic chronic obstructive pulmonary disease: two randomized clinical trials. Lancet 2009; 374: 684-695.
8 Diamant Z, Spina D. PDE4-inhibitors: a novel, targeted therapy for obstructive airways disease. Pulm Pharmacol Ther 2011; 24: 353-360.

9 Rennard SI, Calverley PM, Goehring UM, et al. Reduction of exacerbations by the PDE4 inhibitor roflumilast - the importance of defining different subsets of patients with COPD. Respir Res 2011; 12: 18.

10 Bateman ED, Rabe KF, Calverley PM, et al. Roflumilast with long-acting $\beta_{2}$-agonists for COPD: influence of exacerbation history. Eur Respir J 2011; 38: 553-560.

11 Lamontagne S, Meadows E, Luk P, et al. Localization of phosphodiesterase- 4 isoforms in the medulla and nodose ganglion of the squirrel monkey. Brain Res 2001; 920: 84-96.

12 Jin SL, Conti M. Induction of the cyclic nucleotide phosphodiesterase PDE4B is essential for LPS-activated TNF-a responses. Proc Natl Acad Sci USA 2002; 99: 7628-7633.

13 Burgin AB, Magnusson OT, Singh J, et al. Design of phosphodiesterase 4D (PDE4D) allosteric modulators for enhancing cognition with improved safety. Nat Biotechnol 2010; 28: 63-70.

14 Danto S, Wei GC, Gill J. A randomized, double-blind, placebocontrolled, parallel group, six-week study of the efficacy and safety of tofimilast dry powder for inhalation (DPI) in adults with COPD. Am J Respir Crit Care Med 2007; 175: A131.

15 Gutke HJ, Guse JH, Khobzaoui M, et al. AWD-12-281(inhaled) (elbion/ GlaxoSmithKline). Curr Opin Investig Drugs 2005; 6: 1149-1158.

16 Vestbo J, Tan L, Atkinson G, et al. A controlled trial of 6-weeks' treatment with a novel inhaled phosphodiesterase type-4 inhibitor in COPD. Eur Respir J 2009; 33: 1039-1044.

17 Boswell-Smith V, Spina D, Oxford AW, et al. The pharmacology of two novel long-acting phosphodiesterase $3 / 4$ inhibitors, RPL554 [9,10-dimethoxy-2(2,4,6-trimethylphenylimino)-3-(n-carbamoyl-2aminoethyl)-3,4,6,7-tetrahydro-2H-pyrimido[6,1-a]isoquinolin-4one] and RPL565 [6,7-dihydro-2-(2,6-diisopropylphenoxy)-9,10dimethoxy-4H-pyrimido[6,1-a]isoquinolin-4-one]. J Pharmacol Exp Ther 2006; 318: 840-848.

18 Séguin RM, Ferrari N. Emerging oligonucleotide therapies for asthma and chronic obstructive pulmonary disease. Expert Opin Investig Drugs 2009; 18: 1505-1517.

19 Sullivan GW. Adenosine $\mathrm{A}_{2 \mathrm{~A}}$ receptor agonists as anti-inflammatory agents. Curr Opin Investig Drugs 2003; 4: 1313-1319.

20 Haskó G, Linden J, Cronstein B, et al. Adenosine receptors: therapeutic aspects for inflammatory and immune diseases. Nat Rev Drug Discov 2008; 7: 759-770.

21 Flamand N, Boudreault S, Picard S, et al. Adenosine, a potent natural suppressor of arachidonic acid release and leukotriene biosynthesis in human neutrophils. Am J Respir Crit Care Med 2000; 161: S88-S94.

22 Trevethick MA, Mantell SJ, Stuart EF, et al. Treating lung inflammation with agonists of the adenosine $\mathrm{A} 2 \mathrm{~A}$ receptor: promises, problems and potential solutions. Br J Pharmacol 2008; 155: 463-474.

23 Thomas GS, Tammelin BR, Schiffman GL, et al. Safety of regadenoson, a selective adenosine $\mathrm{A}_{2 \mathrm{~A}}$ agonist, in patients with chronic obstructive pulmonary disease: a randomized, doubleblind, placebo-controlled trial (RegCOPD trial). J Nucl Cardiol 2008; 15: 319-328.

24 El-Tayeb A, Iqbal J, Behrenswerth A, et al. Nucleoside-5' -monophosphates as prodrugs of adenosine A2A receptor agonists activated by ecto-5'-nucleotidase. J Med Chem 2009; 52: 7669-7677.

25 Samsel M, Dzierzbicka K. Therapeutic potential of adenosine analogues and conjugates. Pharmacol Rep 2011; 63: 601-617.

26 Geng JG. Directional migration of leukocytes: their pathological roles in inflammation and strategies for development of antiinflammatory therapies. Cell Res 2001; 11: 85-88.

27 Cheung LS, Raman PS, Balzer EM, et al. Biophysics of selectinligand interactions in inflammation and cancer. Phys Biol 2011; 8: 015013. 
28 Barnes PJ. COPD: is there light at the end of the tunnel? Curr Opin Pharmacol 2004; 4: 263-272.

29 Davenpeck KL, Berens KL, Dixon RA, et al. Inhibition of adhesion of human neutrophils and eosinophils to P-selectin by the sialyl Lewis antagonist TBC1269: preferential activity against neutrophil adhesion in vitro. J Allergy Clin Immunol 2000; 105: 769-775.

30 Radi ZA, Caverly JM, Dixon RA, et al. Effects of the synthetic selectin inhibitor TBC1269 on tissue damage during acute Mannheimia haemolytica-induced pneumonia in neonatal calves. Am J Vet Res 2001; 62: 17-22.

31 Bock D, Beeh K, Beier J, et al. Safety and efficacy of the inhaled pan-selectin antagonist bimosiamose in patients with COPD. Eur Respir J 2007; 30: Suppl. S1, 613s.

32 Watz H, Bock D, Meyer M, et al. Inhaled pan-selectin antagonist bimosiamose in COPD: A double-blind, randomized, placebocontrolled phase II study. Eur Respir J 2011; 38: Suppl. S5, 818s-819s.

33 Bedard PW, Kaila N. Selectin inhibitors: a patent review. Expert Opin Ther Pat 2010; 20: 781-793.

34 Matera MG, Calzetta L, Cazzola M. TNF- $\alpha$ inhibitors in asthma and COPD: we must not throw the baby out with the bath water. Pulm Pharmacol Ther 2010; 23: 121-128.

35 van der Vaart $\mathrm{H}$, Koeter $\mathrm{GH}$, et al. First study of infliximab treatment in patients with chronic obstructive pulmonary disease. Am J Respir Crit Care Med 2005; 172: 465-469.

36 Rennard SI, Fogarty C, Kelsen S, et al. The safety and efficacy of infliximab in moderate-to-severe chronic obstructive pulmonary disease. Am J Respir Crit Care Med 2007; 175: 926-934.

37 Dentener MA, Creutzberg EC, Pennings H-J, et al. Effect of infliximab on local and systemic inflammation in chronic obstructive pulmonary disease: a pilot study. Respiration 2008; 76: $275-282$.

38 Suissa S, Ernst P, Hudson M. TNF- $\alpha$ antagonists and the prevention of hospitalisation for chronic obstructive pulmonary disease. Pulm Pharmacol Ther 2008; 21: 234-238.

39 Mahler DA, Huang S, Tabrizi M, et al. Efficacy and safety of a monoclonal antibody recognizing interleukin-8 in COPD: a pilot study. Chest 2004; 126: 926-934.

40 Yang XD, Corvalan JR, Wang $\mathrm{P}$, et al. Fully human antiinterleukin-8 monoclonal antibodies: potential therapeutics for the treatment of inflammatory disease states. J Leukoc Biol 1999; 66: 401-410.

41 Proudfoot AE, Handel TM, Johnson Z, et al. Glycosaminoglycan binding and oligomerization are essential for the in vivo activity of certain chemokines. Proc Natl Acad Sci USA 2003; 100: 1885-1890.

42 D'Elios MM, Del Prete G, Amedei A. Interfering with chemokines and chemokine receptors as potential new therapeutic strategies. Expert Opin Ther Patents 2008; 18: 309-325.

43 Donnelly LE, Rogers DF. Therapy for chronic obstructive pulmonary disease in the 21st century. Drugs 2003; 63: 1973-1998.

44 Barnes PJ. The cytokine network in chronic obstructive pulmonary disease. Am J Respir Cell Mol Biol 2009; 41: 631-638.

45 Koelink PJ, Overbeek SA, Braber S, et al. Targeting chemokine receptors in chronic inflammatory diseases: an extensive review. Pharmacol Ther 2012; 133: 1-18.

46 Holz O, Khalilieh S, Ludwig-Sengpiel A, et al. SCH527123, a novel CXCR2 antagonist, inhibits ozone-induced neutrophilia in healthy subjects. Eur Respir J 2010; 35: 564-570.

47 Lazaar AL, Sweeney LE, MacDonald AJ, et al. SB-656933, a novel CXCR2 selective antagonist, inhibits ex vivo neutrophil activation and ozone-induced airway inflammation in humans. $\mathrm{Br} \mathrm{J}$ Clin Pharmacol 2011; 72: 282-293.

48 Pease JE, Sabroe I. The role of interleukin- 8 and its receptors in inflammatory lung disease. Implications for therapy. Am J Respir Med 2002; 1: 19-25.

49 Saetta $\mathrm{M}$, Mariani $\mathrm{M}$, Panina-Bordignon $\mathrm{P}$, et al. Increased expression of the chemokine receptor CXCR3 and its ligand
CXCL10 in peripheral airways of smokers with chronic obstructive pulmonary disease. Am J Respir Crit Care Med 2002; 165: 1404-1409.

50 Zhang J, Patel JM. Role of the CX3CL1-CX3CR1 axis in chronic inflammatory lung diseases. Int J Clin Exp Med 2010; 3: 233-244.

51 McComb JG, Ranganathan M, Liu XH, et al. CX3CL1 up-regulation is associated with recruitment of CX3CR1+ mononuclear phagocytes and $\mathrm{T}$ lymphocytes in the lungs during cigarette smokeinduced emphysema. Am J Pathol 2008; 173: 949-961.

52 Ning W, Li CJ, Kaminski N, et al. Comprehensive gene expression profiles reveal pathways related to the pathogenesis of chronic obstructive pulmonary disease. Proc Natl Acad Sci USA 2004; 101: 14895-14900.

53 Mionnet C, Buatois V, Kanda A, et al. CXCR1 is required for airway inflammation by promoting $\mathrm{T}$ helper cell survival and maintenance in inflamed lung. Nat Med 2010; 16: 1305-1313.

54 Owen C. Chemokine receptors in airway disease: which receptors to target? Pulm Pharmacol Ther 2001; 14: 193-202.

55 Horvath C, Welt FG, Nedelman M, et al. Targeting CCR2 or CD18 inhibits experimental in-stent restenosis in primates: inhibitory potential depends on type of injury and leukocytes targeted. Circ Res 2002; 90: 488-494.

56 Xia M, Sui Z. Recent developments in CCR2 antagonists. Expert Opin Ther Pat 2009; 19: 295-303.

57 Edwards MR, Bartlett NW, Clarke D, et al. Targeting the NF-кB pathway in asthma and chronic obstructive pulmonary disease. Pharmacol Ther 2009; 121: 1-13.

58 Ghosh S, Karin M. Missing pieces in the NF-kappaB puzzle. Cell 2002; 109: S81-S96.

59 Delhase M, Li N, Karin M. Kinase regulation in inflammatory response. Nature 2000; 406: 367-368.

60 Suzuki J, Ogawa M, Muto S, et al. Novel IкB kinase inhibitors for treatment of nuclear factor- $\mathrm{kB}$-related diseases. Expert Opin Investig Drugs 2011; 20: 395-405.

61 Keslacy S, Tliba O, Baidouri $\mathrm{H}$, et al. Inhibition of tumor necrosis factor- $\alpha$-inducible inflammatory genes by interferon- $\gamma$ is associated with altered nuclear factor- $\mathrm{KB}$ transactivation and enhanced histone deacetylase activity. Mol Pharmacol 2007; 71: 609-618.

62 Goto K, Chiba Y, Misawa M. IL-13 induces translocation of NF$\kappa \mathrm{B}$ in cultured human bronchial smooth muscle cells. Cytokine 2009; 46: 96-99.

63 Catley MC, Sukkar MB, Chung KF, et al. Validation of the antiinflammatory properties of small-molecule IкB kinase (IKK)-2 inhibitors by comparison with adenoviral-mediated delivery of dominant-negative IKK1 and IKK2 in human airways smooth muscle. Mol Pharmacol 2006; 70: 697-705.

64 Gill JS, Zhu X, Moore MJ, et al. Effects of NFkB decoy oligonucleotides released from biodegradable polymer microparticles on a glioblastoma cell line. Biomaterials 2002; 23: 2773-2781.

65 Pelaia G, Cuda G, Vatrella A, et al. Mitogen-activated protein kinases and asthma. J Cell Physiol 2005; 202: 642-653.

66 Renda T, Baraldo S, Pelaia G, et al. Increased activation of p38 MAPK in COPD. Eur Respir J 2008; 31: 62-69.

67 Stellato C. Post-transcriptional and nongenomic effects of glucocorticoids. Proc Am Thorac Soc 2004; 1: 255-263.

68 Barnes PJ. Novel signal transduction modulators for the treatment of airway diseases. Pharmacol Ther 2006; 109: 238-245.

69 Shieven GL. The biology of p38 kinase: a central role in inflammation. Curr Top Med Chem 2005; 5: 921-928.

70 Chopra P, Kanoje V, Semwal A, et al. Therapeutic potential of inhaled p38 mitogen-activated protein kinase inhibitors for inflammatory pulmonary diseases. Expert Opin Investig Drugs 2008; 17: 1411-1425.

71 Chung KF. p38 mitogen-activated protein kinase pathways in asthma and COPD. Chest 2011; 139: 1470-1479.

72 Pettus LH, Wurz RP. Small-molecule p38 MAP kinase inhibitors for the treatment of inflammatory diseases: novel structures and 
developments during 2006-2008. Curr Top Med Chem 2008; 8: 1452-1467.

73 Branger J, Van den Blink B, Weijer S, et al. Antiinflammatory effects of a p38 mitogen-activated protein kinase inhibitor during human endotoxemia. J Immunol 2002; 168: 4070-4077.

74 Schreiber S, Feagan B, D'Haens G, et al. Oral p38 mitogenactivated protein kinase inhibition with BIRB 796 for active Crohn's disease: a randomized, double-blind, placebo-controlled trial. Clin Gastroenterol Hepatol 2006; 4: 325-334.

75 Singh D, Smyth L, Borrill Z, et al. A randomized, placebocontrolled study of the effects of the p38 MAPK inhibitor SB681323 on blood biomarkers of inflammation in COPD patients. J Clin Pharmacol 2010; 50: 94-100.

76 Tan E, Jones I, Tweedy S, et al. The novel oral p38 inhibitor, PH797804, inhibits inhaled lipopolysaccharide (LPS)-induced airway and systemic inflammatory markers in healthy subjects. Am J Respir Crit Care Med 2011; 183: A2554.

77 Barnes N, Pavord I, Maden C, et al. Evaluation of an oral p38 mitogen activated protein kinase (MAPK inhibitor) SB-681323 in COPD. Eur Respir J 2009; 34: Suppl. S3, 648s.

78 MacNee W, Allan R, Jones I, et al. A randomised, placebo controlled trial of 6 weeks' treatment with a novel oral p38 inhibitor in patients with COPD. Eur Respir J 2010; 36: Suppl. S4, 718s.

79 Zhang J, Shen B, Lin A. Novel strategies for inhibition of the p38 MAPK pathway. Trends Pharmacol Sci 2007; 28: 286-295.

80 Perry JJ, Harris RM, Moiani D, et al. p38 $\alpha$ MAP kinase C-terminal domain binding pocket characterized by crystallographic and computational analyses. J Mol Biol 2009; 391: 1-11.

81 Millan DS, Bunnage ME, Burrows JL, et al. Design and synthesis of inhaled p38 inhibitors for the treatment of chronic obstructive pulmonary disease. J Med Chem 2011; 54: 7797-7814.

82 Cohen P. Targeting protein kinases for the development of antiinflammatory drugs. Curr Opin Cell Biol 2009; 21: 317-324.

83 Duraisamy S, Bajpai M, Bughani U, et al. MK2: a novel molecular target for anti-inflammatory therapy. Expert Opin Ther Targets 2008; 12: 921-936.

84 Cantley LC. The phosphoinositide 3-kinase pathway. Science 2002; 296: 1655-1657.

85 Thomas MJ, Smith A, Head DH, et al. Airway inflammation: chemokine-induced neutrophilia and the class I phosphoinositide 3-kinases. Eur J Immunol 2005; 35: 1283-1291.

86 Sapey E, Stockley JA, Greenwood H, et al. Behavioural and structural differences in migrating peripheral neutrophils from patients with COPD. Am J Respir Crit Care Med 2011; 183: 1176-1186.

87 Marwick JA, Chung KF, Adcock IM. Phosphatidylinositol 3kinase isoforms as targets in respiratory disease. Ther Adv Respir Dis 2010; 4: 19-34.

88 Kulkarni S, Sitaru C, Jakus Z, et al. PI3K $\beta$ plays a critical role in neutrophil activation by immune complexes. Sci Signal 2011; 4: ra23.

89 Ghigo A, Damilano F, Braccini L, et al. PI3K inhibition in inflammation: toward tailored therapies for specific diseases. Bioessays 2010; 32: 185-196.

90 Doukas J, Eide L, Stebbins K, et al. Aerosolized phosphoinositide 3-kinase $\gamma / \delta$ inhibitor TG100-115 [3-[2,4-diamino-6-(3-hydroxyphenyl) pteridin-7-yl]phenol] as a therapeutic candidate for asthma and chronic obstructive pulmonary disease. J Pharmacol Exp Ther 2009; 328: 758-765.

91 Reutershan J, Saprito MS, Wu D, et al. Phosphoinositide-3 kinase $\gamma$ required for LPS-induced transepithelial neutrophil trafficking in the lung. Eur Respir J 2010; 35: 1137-1147.

92 Maus UA, Backi M, Winter C, et al. Importance of phosphoinositide 3-kinase $\gamma$ in the host defense against pneumococcal infection. Am J Respir Crit Care Med 2007; 175: 958-966.

93 Crooks SW, Stockley RA. Leukotriene $\mathrm{B}_{4}$. Int J Biochem Cell Biol 1998; 30: 173-178.
94 Hicks A, Monkarsh SP, Hoffman AF, et al. Leukotriene B4 receptor antagonists as therapeutics for inflammatory disease: preclinical and clinical developments. Exp Opin Invest Drugs 2007; 16: 1909-1920.

95 Corhay JL, Henket M, Nguyen D, et al. LTB4 contributes to exhaled breath condensate and sputum neutrophil chemotaxis in COPD. Chest 2009; 136: 1047-1054.

96 Profita M, Sala A, Riccobono L, et al. 15(S)-HETE modulates $\mathrm{LTB}_{4}$ production and neutrophil chemotaxis in chronic bronchitis. Am J Physiol Cell Physiol 2000; 279: C1249-C1258.

97 Devchand PR, Keller H, Peters JM, et al. The PPAR $\alpha$-leukotriene B4 pathway to inflammation control. Nature 1996; 384: 39-43.

98 Grönke L, Beeh KM, Cameron R, et al. Effect of the oral leukotriene B4 receptor antagonist LTB019 on inflammatory sputum markers in patients with chronic obstructive pulmonary disease. Pulm Pharmacol Ther 2008; 21: 409-417.

99 Hicks A, Goodnow R Jr, Cavallo G, et al. Effects of LTB4 receptor antagonism on pulmonary inflammation in rodents and nonhuman primates. Prostaglandins Other Lipid Mediat 2010; 92: 33-43.

100 Kilfeather S. 5-Lipoxygenase inhibitors for the treatment of COPD. Chest 2002; 121: Suppl. S, 197S-200S.

101 Berger W, De Chandt MT, Cairns CB. Zileuton: clinical implications of 5-lipoxygenase inhibition in severe airway disease. Int J Clin Pract 2007; 61: 663-676.

102 Gompertz S, Stockley RA. A randomized, placebo-controlled trial of a leukotriene synthesis inhibitor in patients with COPD. Chest 2002; 122: 289-294.

103 Bernstein JA, Liu N, Knorr BA, et al. MK-0633, a potent 5lipoxygenase inhibitor, in chronic obstructive pulmonary disease. Respir Med 2011; 105: 392-401.

104 Woodruff PG, Albert RK, Bailey WC, et al. Randomized trial of zileuton for treatment of COPD exacerbations requiring hospitalization. COPD 2011; 8: 21-29.

105 Belvisi MG, Mitchell JA. Targeting PPAR receptors in the airway for the treatment of inflammatory lung disease. $\mathrm{Br} J$ Pharmacol 2009; 158: 994-1003.

106 van Bilsen M, van Nieuwenhoven FA. PPARs as therapeutic targets in cardiovascular disease. Expert Opin Ther Targets 2010, 14: 1029-1045.

107 Narala VR, Adapala RK, Suresh MV, et al. Leukotriene $B_{4}$ is a physiologically relevant endogenous peroxisome proliferatoractivated receptor- $\alpha$ agonist. J Biol Chem 2010; 285: 22067-22074.

108 Belvisi MG, Hele DJ, Birrell MA. Peroxisome proliferatoractivated receptor $\gamma$ agonists as therapy for chronic airway inflammation. Eur J Pharmacol 2006; 533: 101-109.

109 Milam JE, Keshamouni VG, Phan SH, et al. PPAR- $\gamma$ agonists inhibit profibrotic phenotypes in human lung fibroblasts and bleomycin induced pulmonary fibrosis. Am J Physiol Lung Cell Mol Physiol 2008; 294: L891-L901.

110 Nissen SE, Wolski K. Rosiglitazone revisited: an updated metaanalysis of risk for myocardial infarction and cardiovascular mortality. Arch Intern Med 2010; 170: 1191-1201.

111 Velayudhan J, Haran AC, Wright CD. The non-thiazolidinedione PPAR $\gamma$ ligand, GW1929 displays anti-inflammatory in poly(I:C)induced air-liquid interface human bronchial epithelial cells. Am J Respir Crit Care Med 2011; 183: A2827.

112 Barnes PJ, Celli BR. Systemic manifestations and comorbidities of COPD. Eur Respir J 2009; 33: 1165-1185.

113 Murphy DM, Forrest IA, Curran D, et al. Macrolide antibiotics and the airway: antibiotic or non-antibiotic effects? Expert Opin Investig Drugs 2010; 19: 401-414.

114 Cazzola M, Matera MG, Blasi F. Macrolide and occult infection in asthma. Curr Opin Pulm Med 2004; 10: 7-14.

115 Altenburg J, de Graaff CS, van der Werf TS, et al. Immunomodulatory effects of macrolide antibiotics - part 1: biological mechanisms. Respiration 2011; 81: 67-74. 
116 Desaki M, Okazaki H, Sunazuka T, et al. Molecular mechanisms of anti-inflammatory action of erythromycin in human bronchial epithelial cells: possible role in the signaling pathway that regulates nuclear factor-kB activation. Antimicrob Agents Chemother 2004; 48: 1581-1585.

117 Jang YJ, Kwon HJ, Lee BJ. Effect of clarithromycin on rhinovirus16 infection in A549 cells. Eur Respir J 2006; 27: 12-19.

118 Tsai WC, Rodriguez ML, Young KS. Azithromycin blocks neutrophil recruitment in Pseudomonas endobronchial infection. Am J Respir Crit Care Med 2004; 170: 1331-1339.

119 Ivetić Tkalcević V, Bosnjak B, Hrvacić B, et al. Anti-inflammatory activity of azithromycin attenuates the effects of lipopolysaccharide administration in mice. Eur J Pharmacol 2006; 539: 131-138.

120 Nakanishi Y, Kobayashi D, Asano Y, et al. Clarithromycin prevents smoke-induced emphysema in mice. Am J Respir Crit Care Med 2009; 179: 271-278.

121 Parnham MJ, Culic O, Erakovic V. Modulation of neutrophil and inflammation markers in chronic obstructive pulmonary disease by short-term azithromycin treatment. Eur J Pharmacol 2005; 517: 132-143.

122 Marjanović N, Bosnar M, Michielin F, et al. Macrolide antibiotics broadly and distinctively inhibit cytokine and chemokine production by COPD sputum cells in vitro. Pharmacol Res 2011; 63: 389-397.

123 Seemungal TA, Wilkinson TM, Hurst JR, et al. Long-term erythromycin therapy is associated with decreased chronic obstructive pulmonary disease exacerbations. Am J Respir Crit Care Med 2008; 178: 1139-1147.

124 Albert RK, Connett J, Bailey WC, et al. Azithromycin for prevention of exacerbations of COPD. N Engl J Med 2011; 365: 689-698.

125 Fecik RA, Nguyen PL, Venkatraman L. Approaches to the synthesis of immunolides: selective immunomodulatory macrolides for cystic fibrosis. Curr Opin Drug Discov Devel 2005; 8: 741-747.

126 Zhou Q, Liao JK. Pleiotropic effects of statins. Basic research and clinical perspectives. Circ J 2010; 74: 818-826.

127 Hothersall E, McSharry C, Thomson NC. Potential therapeutic role for statins in respiratory disease. Thorax 2006; 61: 729-734.

128 Bonetti PO, Lerman LO, Napoli C, et al. Statin effects beyond lipid lowering - are they clinically relevant? Eur Heart J 2003; 24 225-248.

129 Wright JL, Zhou S, Preobrazhenska O, et al. Statin reverses smokeinduced pulmonary hypertension and prevents emphysema but not airway remodeling. Am J Respir Crit Care Med 2011; 183: 50-58.

130 Keddissi JI, Younis WG, Chbeir EA, et al. The use of statins and lung function in current and former smokers. Chest 2007; 132: 1764-1771.

131 Dobler CC, Wong KK, Marks GB. Associations between statins and COPD: a systematic review. BMC Pulm Med 2009; 9: 32.

132 Bartziokas K, Papaioannou AI, Minas M, et al. Statins and outcome after hospitalization for COPD exacerbation: a prospective study. Pulm Pharmacol Ther 2011; 24: 625-631.

133 Barnes PJ. Mechanisms and resistance in glucocorticoid control of inflammation. J Steroid Biochem Mol Biol 2010; 120: 76-85.

134 Biswas S, Rahman I. Modulation of steroid activity in chronic inflammation: a novel anti-inflammatory role for curcumin. $\mathrm{Mol}$ Nutr Food Res 2008; 52: 987-994.
135 Webster JI, Carlstedt-Duke J. Involvement of multidrug resistance proteins (MDR) in the modulation of glucocorticoid response. J Steroid Biochem Mol Biol 2002; 82: 277-288.

136 Nobili S, Landini I, Giglioni B, et al. Pharmacological strategies for overcoming multidrug resistance. Curr Drug Targets 2006; 7: 861-879.

137 Hoi AY, Iskander MN, Morand EF. Macrophage migration inhibitory factor: a therapeutic target across inflammatory diseases. Inflamm Allergy Drug Targets 2007; 6: 183-190.

138 Vassilakopoulos T, Roussos C, Zakynthinos S. Is loaded breathing an inflammatory stimulus? Curr Opin Crit Care 2005; 11: 1-9.

139 Suzuki J, Suzuki S, Okubo T. Effects of fenoterol on inspiratory effort sensation and fatigue during inspiratory threshold loading. J Appl Physiol 1996; 80: 727-733.

140 Hatipoğlu U, Laghi F, Tobin MJ. Does inhaled albuterol improve diaphragmatic contractility in patients with chronic obstructive pulmonary disease? Am J Respir Crit Care Med 1999; 160: 1916-1921.

141 O'Donnell DE, Flüge T, Gerken F, et al. Effects of tiotropium on lung hyperinflation, dyspnea and exercise tolerance in patients with COPD. Eur Respir J 2004; 23: 832-840.

142 Powrie DJ, Wilkinson TM, Donaldson GC, et al. Effect of tiotropium on sputum and serum inflammatory markers and exacerbations in COPD. Eur Respir J 2007; 30: 472-478.

143 Aubier M, De Troyer A, Sampson M, et al. Aminophylline improves diaphragmatic contractility. $N$ Engl J Med 1981; 305 249-252.

144 Barnes PJ. Theophylline: new perspectives for an old drug. Am J Respir Crit Care Med 2003; 167: 813-818.

145 Rahman I. Pharmacological antioxidant strategies as therapeutic interventions for COPD. Biochim Biophys Acta 2012; 1822: 714-728.

146 Fischer BM, Pavlisko E, Voynow JA. Pathogenic triad in COPD oxidative stress, protease-antiprotease imbalance, and inflammation. Int J Chron Obstruct Pulmon Dis 2011; 6: 413-421.

147 Djekic UV, Gaggar A, Weathington NM. Attacking the multitiered proteolytic pathology of COPD: new insights from basic and translational studies. Pharmacol Ther 2009; 121: 132-146.

148 Lucas SD, Costa E, Guedes RC, et al. Targeting COPD: advances on low-molecular-weight inhibitors of human neutrophil elastase. Med Res Rev 2011 [Epub ahead of print DOI: 10.1002/ med.20247].

149 Groutas WC, Dou D, Alliston KR. Neutrophil elastase inhibitors. Expert Opin Ther Pat 2011; 21: 339-354.

150 Kuna P, Jenkins M, O’Brien CD, et al. AZD9668, a neutrophil elastase inhibitor, plus ongoing budesonide/formoterol in patients with COPD. Respir Med 2012; 106: 531-539.

151 Celli BR, MacNee W. Standards for the diagnosis and treatment of patients with COPD: a summary of the ATS/ERS position paper. Eur Respir J 2004; 23: 932-946.

152 Churg A, Cosio M, Wright JL. Mechanisms of cigarette smokeinduced COPD: insights from animal models. Am J Physiol Lung Cell Mol Physiol 2008; 294: L612-L631.

153 Martinez FJ, Donohue JF, Rennard SI. The future of chronic obstructive pulmonary disease treatment - difficulties of and barriers to drug development. Lancet 2011; 378: 1027-1037. 